\title{
In vitro tissue-engineered adipose constructs for modeling disease
}

\author{
Connor S. Murphy ${ }^{1,2,4}$, Lucy Liaw Li, $^{1,3,4}$ and Michaela R. Reagan ${ }^{1,2,3,4^{*}}$ (D)
}

\begin{abstract}
Adipose tissue is a vital tissue in mammals that functions to insulate our bodies, regulate our internal thermostat, protect our organs, store energy (and burn energy, in the case of beige and brown fat), and provide endocrine signals to other organs in the body. Tissue engineering of adipose and other soft tissues may prove essential for people who have lost this tissue from trauma or disease. In this review, we discuss the applications of tissue-engineered adipose tissue specifically for disease modeling applications. We provide a basic background to adipose depots and describe three-dimensional (3D) in vitro adipose models for obesity, diabetes, and cancer research applications. The approaches to engineering 3D adipose models are diverse in terms of scaffold type (hydrogel-based, silk-based and scaffold-free), species of origin (H. sapiens and M. musculus) and cell types used, which allows researchers to choose a model that best fits their application, whether it is optimization of adipocyte differentiation or studying the interaction of adipocytes and other cell types like endothelial cells. In vitro 3D adipose tissue models support discoveries into the mechanisms of adipose-related diseases and thus support the development of novel anti-cancer or anti-obesity/diabetes therapies.
\end{abstract}

Keywords: In vitro models, Tissue engineering, Tissue-engineered adipose tissue, Adipocytes, 3D culture, Fat, Cancer, Obesity, Type 2 diabetes

\section{Background}

The road to US Food and Drug Administration approval for a new pharmaceutical is long and arduous; the process often lasts for over 10 years, costs an average of 2.8 billion dollars, and has only a $\sim 10 \%$ success rate $[1,2]$. This low success rate can be attributed to the fact that drugs often exhibit different effects in clinical trials than in earlier stages of the pipeline (e.g. animal and two-dimensional (2D) cell culture assays). Although 2D cell culture has contributed to the majority of discoveries in modern day cell biology, these cultures do not model the microenvironment cells encounter naturally: a three-dimensional (3D) matrix with abundant cell-to-cell interactions, unique mechanical properties, and an extensive extracellular matrix. Tissue-engineered 3D models have therefore been used in an attempt to more accurately

\footnotetext{
* Correspondence: mreagan@mmc.org; Mreagan@mmc.org

${ }^{1}$ Maine Medical Center Research Institute, Scarborough, ME, USA

${ }^{2}$ University of Maine Graduate School of Biomedical Science and

Engineering, Orono, ME, USA

Full list of author information is available at the end of the article
}

model the in vivo microenvironment. Indeed, various 3D models of cancer, adipose tissue, and many other tissues have been shown to more closely mimic their in vivo counterparts in terms of cellular morphology and global expression profiles [3-5]. This review aims to assess recent advances in 3D modeling for diseases centered on adipose tissue such as: obesity, type 2 diabetes, and cancer adjacent to adipocytes. Although 3D adipose models are also used for soft tissue reconstruction after physical trauma or tumor resections, these topics are outside the scope of disease-based models covered in this review, but are thoroughly reviewed elsewhere [6-8].

\section{Main text \\ Distinct adipose tissues and their functions \\ Much like the waistlines of the world's population, the literature regarding the distinct types of adipose tissue has been expanding over the years. The growth in litera- ture is partially due to the discovery of 5 distinct adipose tissue types: white adipose tissue (WAT), brown adipose}


tissue (BAT), beige/brite adipose tissue, bone marrow adipose tissue (BMAT), and perivascular adipose tissue (PVAT). Given the rich literature on the subject and the limited scope of this review, we will only highlight a few major features of each depot here. A more detailed account of each depot can be found in these comprehensive reviews [9-13].

\section{White adipose tissue (WAT)}

Adipocytes are the primary cellular component of adipose tissue, but adipose tissue is also composed of nervous and connective tissue and vasculature. Adipocytes found in WAT possess the morphology commonly associated with a fat cell; a cell with one large lipid droplet (LD), which occupies the majority of cellular space, forcing the nucleus and cytoplasm to the periphery of the cell. The two main WAT depots, visceral (VAT) and subcutaneous (SAT), are functionally different. VAT is essential for the protection of inner organs and a major contributor to obesity $[14,15]$. Conversely, SAT is primarily responsible for insulation and has been associated with improving insulin sensitivity [16]. Although VAT and SAT appear to have opposing functions, they both regulate energy homeostasis. For energy homeostasis, exogenous energy sources such as glucose are stored as glycogen and subsequently converted into triacylglycerols (TGs), the major component of the energy storing organelle, the lipid droplet, in adipocytes [17]. As the cellular need for energy increases, lipases release TGs causing lipid droplets to degrade, in a process known as lipolysis. TGs are subsequently catabolized into glycerol and fatty acids, which eventually produce adenosine triphosphate (ATP) through glycolysis or $\beta$-oxidation, respectively [18].

The connection between adipocytes and insulin make adipocytes one of the most significant cell types to regulate systemic insulin levels [19]. Insulin bears much of the responsibility for promoting the cellular uptake of glucose through upregulating the glucose transporter, GLUT4 [20]. To promote energy storage, insulin also inhibits lipolysis through the inhibition of protein kinase A (PKA) [21], and it is thus integral for adipocyte maintenance and function [22]. Adipose vascularization and innervation also reflect the crosstalk that occurs between adipose and distant tissues. For decades, adipocytes were assumed to simply function as cells that store and release energy, and provide mechanical and thermal insulation. However, the complexity of adipocytes was revealed when substances specifically secreted by adipocytes, known as adipokines, were identified in the 1980's and 90's [23-25].

The adipokine leptin was found to regulate feeding, fatty acid utilization, and energy balance by serving as a feedback mechanism between adipose and other tissues throughout the body [26-28]. Leptin activates 5 ' adenosine monophosphate-activated protein kinase (AMPK), leading to an increase in fatty acid oxidation and inhibition of the rate-limiting step to lipogenesis, acetyl-CoA carboxylase (ACC) action [29]. Leptin also serves to protect against lipotoxicity by shuttling fatty acids away from non-adipose tissue [30]. Another key adipokine, adiponectin (ADIPOQ), is expressed exclusively by mature adipocytes, supports insulin sensitivity, and has a protective effect against cardiac hypertrophy and atherosclerosis [31-33]. Indeed, adiponectin receptors 1 and 2 (ADIPOR1 and ADIPOR2) have anti-diabetic effects [34]. The broad effects of ADIPOQ on metabolism and cardiac health can be attributed to its formation of trimers, hexamers, and even higher molecular weight forms of the protein [35]. Interestingly, each ADIPOQ complex can act on different pathways; for example, while the trimeric form activates AMPK, the higher molecular weight form activates nuclear factor kappa-lightchain-enhancer of activated B cells (NF-kB) [36, 37]. In addition to leptin and adiponectin providing evidence for adipose tissue as an endocrine organ, the relationship between WAT and the reproductive system highlights this relationship as well.

WAT and the reproductive system undergo extensive bidirectional communication mainly through testosterone and estrogen and have profound effects on one another. Dihydrotesterosterone (DHT) can induce lipolysis and inhibit mesenchymal stem cell (MSC) differentiation into adipocytes [38, 39]. Additionally, knocking out the estrogen receptor can lead to white adipocyte hyperplasia and hypertrophy, while knocking out both the estrogen and androgen receptors results in a global increase in adiposity [40, 41]. WAT influences sex hormone levels as well. White adipocytes can inactivate DHT through the action of alpha-keto reductase family member 1 C2 [42-44]. Also, the loss of function of aromatase, the enzyme that converts testosterone to estradiol, can lead to increased abdominal adiposity and insulin resistance [45]. Adipokines like leptin and adiponectin have been shown to influence reproduction as well [46, 47]. The reproductive system and WAT communicate through the regulation and processing of two major hormones, testosterone and estrogen, and have major effects on human health.

\section{Brown adipose tissue (BAT) and beige adipose tissue}

Brown adipose tissue (BAT), an adipose depot unique to mammals, is found at distinct locations: the major depots of BAT in adult mice and rats can be found in the scapulae and thoracic regions, where they serve as the major source of non-shivering thermogenesis [48]. Similarly, adult human BAT is primarily located in the cervical-supraclavicular depot and is identified by the 
uptake of ${ }^{18} \mathrm{~F}$-fluorodeoxyglucose via positron-emission tomography and computed tomography (PET-CT) due to the propensity of BAT to consume more glucose than other healthy tissues $[49,50]$. Unlike WAT, BAT is multilocular and takes advantage of the mitochondrial membrane protein, uncoupling protein 1 (UCP-1), to produce heat instead of adenosine triphosphate (ATP) during the process of fatty acid oxidation [51, 52]. UCP-1 functions by increasing membrane permeability of the mitochondrial membrane in order to disrupt the proton motive force at the heart of ATP synthesis. BAT is characterized by the high expression of PR domain containing 16 (PRDM16), Peroxisome proliferator-activated receptor gamma coactivator 1 -alpha (PGC-1 $\alpha$ ), type 2 deiodinase (Dio2), and UCP-1 [53, 54]. Brown and white fat also differ in their progenitors, with the lineage of BAT being traced to a myogenic precursor which is $\mathrm{Pax}^{+} / \mathrm{Myf} 5^{+}$, while the WAT progenitor is $\operatorname{Pax}^{-} / \mathrm{Myf5}^{-}[53,55]$.

Beige fat or inducible brown fat, is a prime example of the dynamism that adipocytes exhibit. Upon prolonged cold exposure or adrenergic signaling, a subset of white adipocytes upregulate UCP-1 and adopt a more BATlike phenotype, a process termed "browning" [11, 56]. Browning initiates a switch from a unilocular white adipocyte to a beige adipocyte that is multilocular and thermogenic, and has an increased number of mitochondria. Both browning and BAT may be protective from obesity based on observations that browning in obese strains of mice is decreased compared to strains resistant to obesity, while the thermogenic capacity of BAT remains the same [57, 58]. Additional evidence for the protective effects of beige and brown fat suggests they play a major role in decreasing circulating TG and glucose levels [59]. Deeper investigations into brown and beige fat biology will likely help combat metabolic syndromes like obesity and type 2 diabetes mellitus (T2DM) that are reaching epidemic levels in many countries.

\section{Bone marrow adipose tissue (BMAT)}

Peering into the bone marrow within the long bones of an adult human or mouse, one would observe that 50 $70 \%$ of the bone marrow has distinct yellow hue [60]. This hue is due to the presence of bone marrow adipose tissue (BMAT). BMAT is induced by common medical practices such as the administration thiazolidinediones (such as the anti-diabetic drug, rosiglitazone), radiation, and chemotherapy [61-64]. Studies suggest that BMAT may have a complicated role in global metabolism since BMAT is increased both in obesity and paradoxically, in patients suffering from anorexia nervosa or starvation $[65,66]$. BMAT appears to have a distinct lineage from other adipose depots; bone marrow MSCs that are $\mathrm{CD} 45^{-} / \mathrm{CD} 31^{-} / \mathrm{PdgfRa}^{+} / \mathrm{Scal}^{+}$differentiate into adipocytes [67]. Additionally, BM adipocytes originate from osterix ${ }^{+}$cells while other adipocytes do not [68]. The role of BMAT with respect to global metabolism and the effects of BMAT on the local bone marrow microenvironment remain important questions to address in the field.

\section{Perivascular adipose tissue (PVAT)}

Perivascular adipose tissue, the fat depot adjacent to the adventitia of most arteries, is an integral signaling component of the vascular microenvironment. Expansion of PVAT is associated with obesity and cardiovascular disease in humans, with pathological changes described in patients with localized vasospasm, abdominal aortic aneurysm, and coronary artery disease [69-72]. In addition to its basal ability to store and release fatty acids, PVAT alters: vascular tone, smooth muscle cell proliferation and migration, inflammatory programs, and oxidative stress pathways. PVAT exerts its influence on the surrounding tissues through the secretion of adipokines and cytokines such as leptin, adiponectin, TNF- $\alpha$, and IL-6 [73-76]. Although healthy PVAT is considered vasoprotective, obesity and hyperlipidemia induce changes that can promote vascular disease progression. In a genetic mouse model of atherosclerosis, the PVAT from a apolipoprotein E-null $\left(\mathrm{ApoE}^{-/-}\right)$mouse promoted atherosclerotic plaques in a region where it does not usually form in $\mathrm{ApoE}^{-/-}$mice $[77,78]$. The phenotype of mouse and human PVAT depends on its location. While PVAT near the carotid artery adopts a BAT-like morphology (Fig. 1a and b) it more closely resembles WAT in the mesenteric arteries (Fig. 1c). Indeed, the thermogenic properties and BAT-like expression pattern of thoracic aorta-associated PVAT proved to attenuate atherosclerosis [79], suggesting PVAT as an important source of paracrine regulation in vascular disease. There is some question about how well mouse models of PVAT expansion and pathology can mimic these processes in humans, since aortic PVAT derived from adult humans is morphologically more similar to WAT than BAT. However, it is clear that human aortic PVAT, even from patients with cardiovascular disease, express thermogenic markers including UCP-1, which is absent in human WAT (Fig. 1d). Within the thoracic aorta, PVAT adopts a more BAT-like phenotype (Fig. 1e) [79, 80]. Studies of human PVAT have shown that PVAT-derived adipocyte progenitor cell differentiation is dependent on Rab27a, a GTPase important for secretory vesicle trafficking [81]. One could imagine that the bi-directional communication between PVAT and the blood vessel relies on Rab27a-dependent trafficking and secretion of signaling molecules. These interesting results highlight that the full potential of targeting PVAT with respect to cardiovascular disease and obesity has yet to be realized and requires further study. 


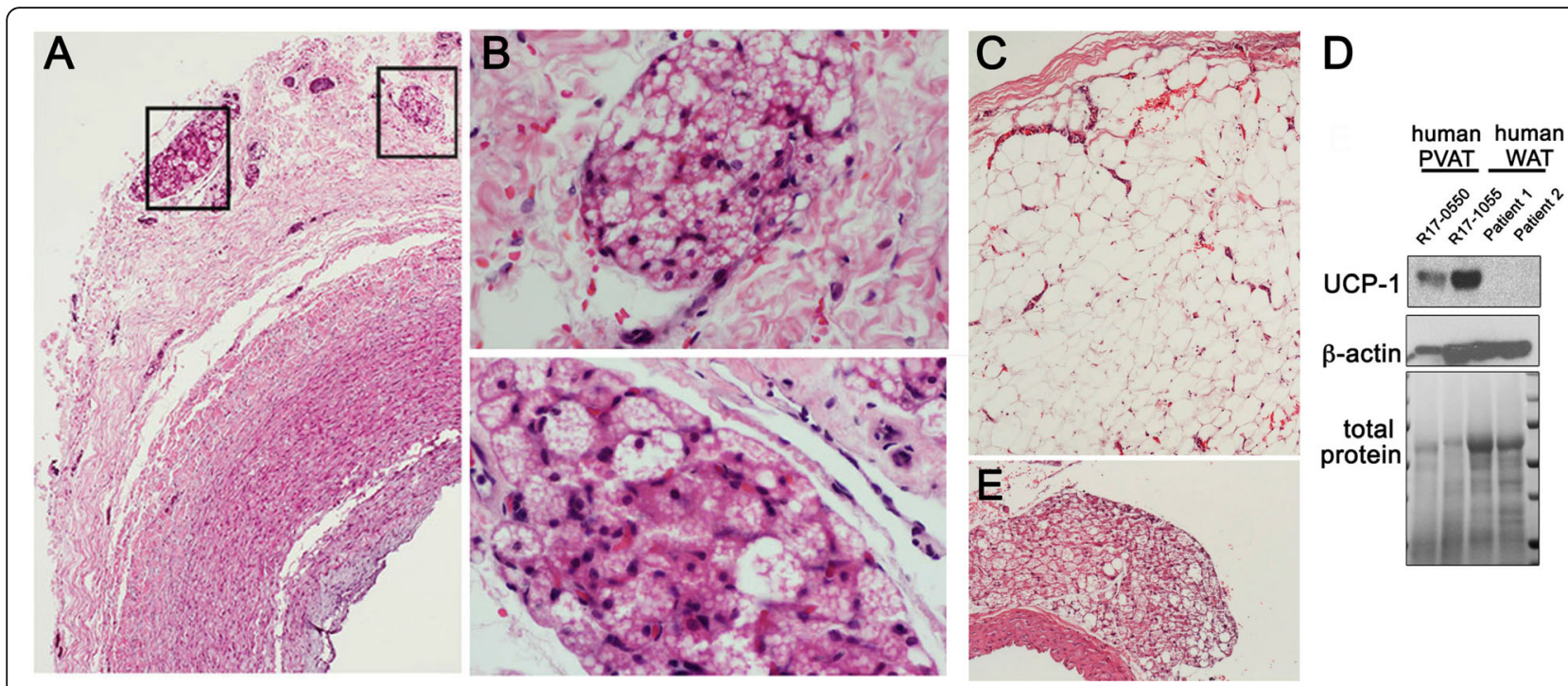

Fig. 1 Human aortic PVAT has features of thermogenic adipose tissue. a Shown is a carotid artery with surrounding adventitia and PVAT from a 1-month old human donor. b Note the pockets of brown-like adipose tissue (boxed), that are morphologically indistinguishable from brown adipose tissue. c Human PVAT surrounding aorta was collected from an adult during open-heart surgery, and morphologically resembles WAT. However, compared to subcutaneous human WAT, human aortic PVAT, even from patients with cardiovascular disease, express the thermogenic adipocyte marker UCP-1. d Western immunoblot of human PVAT and subcutaneous WAT for the indicated proteins. R17-0550 and R17-1055 represent samples from two different patients. Reprinted by permission from RightsLink: Springer Nature, Cardiovascular Drugs and Therapy, Boucher et al. 2018. e Mouse PVAT from the thoracic aorta is shown for comparison, and has a brown fat-like thermogenic phenotype and protein profile

As researchers delved deeper into adipocyte biology, they have come to appreciate that adipocytes are highly sensitive to metabolites, cytokines, and hormones, and can also regulate processes like angiogenesis, inflammation, immunity, reproduction, and cardiac homeostasis $[25,82-89]$. Given that adipose tissue is intimately intertwined in a diverse number of biological processes, it is imperative to understand the intricacies of this amazing tissue.

\section{Adipose-associated disease models Background on 3D models}

Tissue engineers must consider a number of key characteristics that are conducive to constructing 3D tissues in vitro. Pore size is a parameter that positively correlates with nutrient availability and modulates cell proliferation, migration, and matrix deposition. Researchers must also consider the ideal mechanical stiffness for their cell type in question and how that compares to the in vivo environment they are attempting to model. Additionally, the material's degradation properties should be predictable and be able to be manipulated in order to assess the kinetics of culturing cells on that material. Understanding the degradation rate is an important experimental parameter because it can factor into how long cells are able to be cultured. Importantly, the material in question should be biocompatible and induce a cellular response that best reflects that found in vivo
[90-92]. In order to facilitate the study of disease states, cell viability and growth must be able to be maintained for long-term culture. Together, these and other parameters of 3D systems must be considered and effectively designed for researchers to successfully create 3D-based disease models.

\section{Obesity and type II diabetes mellitus}

Obesity is a worldwide health concern that affects roughly a third of the population and costs an estimated \$209.7 billion dollars per year in the United States alone $[93,94]$. Obesity is defined as having a body mass index (BMI) of $>30 \mathrm{~kg} / \mathrm{m}^{2}$, is characterized by excess accumulation of adipose tissue, and is a major risk factor for various health issues including T2DM, cardiovascular disease, and some cancers [95-97]. Obesity has been difficult to study because the regulation of adipocytes is influenced by environmental, genetic, and epigenetic factors, but the development of tissue-engineered models could aid in providing insight into this complicated disease [98-100].

In an effort to increase the capacity of energy storage during caloric excess, adipocytes increase in size, a phenomenon called hypertrophy. Although increases and decreases in adipocyte size based on the nutrition state of the organism is normal, excessive and prolonged adipocyte hypertrophy is often a sign for adipocyte dysfunction and leads to system-wide changes due to an 
altered adipocyte secretome. Although hypertrophic adipocytes have an increased capacity to store lipids, it is insufficient to contend with the extracellular excess of free fatty acids (FFAs). The excess of FFAs induces local lipotoxicity from increases in oxidative, and endoplasmic reticulum (ER) stress and can have system-wide effects as well (Fig. 2a) [101, 102]. The increase in size of adipocytes prevents oxygen from diffusing across the adipose tissue, resulting in a hypoxic microenvironment [103105]. Together, adipocyte hypertrophy, hypoxia, oxidative and ER stress contribute to the increase in the secretion of adipokines and cytokines as well as the differentiation of new adipocytes [106, 107]. An increase in local pro-inflammatory cytokines resulting from adipocyte secretion, necrosis, and lysis leads to immune cell recruitment and chronic inflammation, perpetuating adipocyte dysfunction (Fig. 2b) [108, 109]. When compared to healthy patients, obese individuals also have increased leptin, fasting glucose, TGs, inflammatory markers, insulin concentrations, and decreased high-density lipoproteins (HDLs) in their serum [110]. Together, these factors can lead to additional morbidities including T2DM and cardiovascular disease. Interestingly, there is a subpopulation of obese patients that have an increase in fat mass but lack the risk of metabolic dysfunctions and cardiovascular disease, known as metabolically healthy obese patients [110]. For the purposes of this review, obesity will refer to the metabolically dysfunctional population.

Impaired insulin signaling is at the heart of why type 2 diabetes patients fail to regulate their blood sugar and is intimately linked with obesity [95]. Insulin signaling activates two major pathways through phosphorylation of insulin receptor substrates (IRSs) on tyrosine residues: (1) the phosphatidylinositol 3-kinase $\left(\mathrm{PI}_{3} \mathrm{~K}\right)$-AKT and (2) mitogen activated protein kinase (MAPK) pathways [111]. While the $\mathrm{PI}_{3} \mathrm{~K}-\mathrm{AKT}$ pathway regulates glucose uptake and suppresses gluconeogenesis, the MAPK pathway interacts with $\mathrm{PI}_{3} \mathrm{~K}-\mathrm{AKT}$ to regulate cell growth and differentiation. Insulin signaling is negatively regulated by phosphorylation of serine residues on IRS1 by kinases such as I kappa B kinase beta (IKK- $\beta$ ) and C-jun-N-terminal kinase (JNK1) [111]. Interestingly, ER stressors from FFA signal through IRE1 to activate both IKK and JNK pathways, contributing to insulin resistance. Additionally, blood glucose remains higher in obese individuals due to GLUT4 expression in adipocytes being downregulated by the induction of ER stress [112]. The negative effects of inflammation are further perpetuated by the recruitment of adipose tissue macrophages (ATMs).

Activated stress pathways found in obesity drive the expression of chemokines like $\mathrm{C}$ - $\mathrm{C}$ motif chemokine ligand 2 (CCL2), CCL8, and CCL5, and chemokine receptors (e.g. CCR2 and CCR5), which help recruit macrophages to the dysfunctional tissue [108, 113]. ATMs form crown-like structures around the stressed adipocytes in order to clear debris and excess FFAs [108]. The recruited ATMs secrete both antiinflammatory (interleukin-10 (IL-10) and IL-1) and proinflammatory (tumor necrosis factor- $\alpha$ (TNF- $\alpha$ ), IL-6, and IL-1 $\beta$ ) cytokines, suggesting they can serve both a protective and harmful role in obesity [114]. However, the inflammation caused by ATMs causes further adipocyte dysfunction and impaired insulin signaling, leading to the manifestation of chronic low-grade inflammation. Despite the complexity of obesity and the early stages of tissue-engineered adipose disease models, researchers have made important strides to move the field forward.

\section{Current 3D adipose disease models}

An ideal tissue engineered 3D adipose tissue model would be comprised of each component found in vivo: adipocytes, connective tissue, vasculature, and nerves. Given that determining the ideal conditions for one cell type is technically challenging, the addition of more cell types compounds the complexity of the model. While groups have engineered 3D nervous tissue models, the interaction between adipocytes and nervous tissue in 3D system has been understudied [115-118]. However, the following 3D adipose models could be adapted in the future to support the growth of both cell types. Groups have primarily focused efforts on engineering systems of adipocytes on scaffolds that mimic in vivo connective tissue or scaffold-free models in which the adipocytes secrete their own extracellular matrix with and without endothelial cells. Therefore, the following section will discuss current avascular and vascular 3D adipose disease models in cells derived from both mouse and humans. Please refer to Table 1 for details on each paper cited below regarding adipose-related disease models.

\section{Mouse avascular 3D adipose disease models}

The majority of mouse avascular 3D adipose models use novel substrates or a combination of existing ones to assess the physical properties which best support adipocyte differentiation and function. Motivated to develop a 3D method to compare subcutaneous and visceral fat depots, due to the inefficient differentiation of stem cells isolated from visceral fat, Emont et al. adopted a 3D collagen-based cell culture system [119]. Cell suspensions from mouse inguinal, perigonadal, and SVF fat depots were homogenized and mixed with collagen or plated in collagen-coated 2D wells and allowed to differentiate for 6-7 days to determine if the 3D cultures could enhance the differentiation of visceral fat precursors. Emont et al. showed that 3D culture increased expression of genes associated with differentiated 


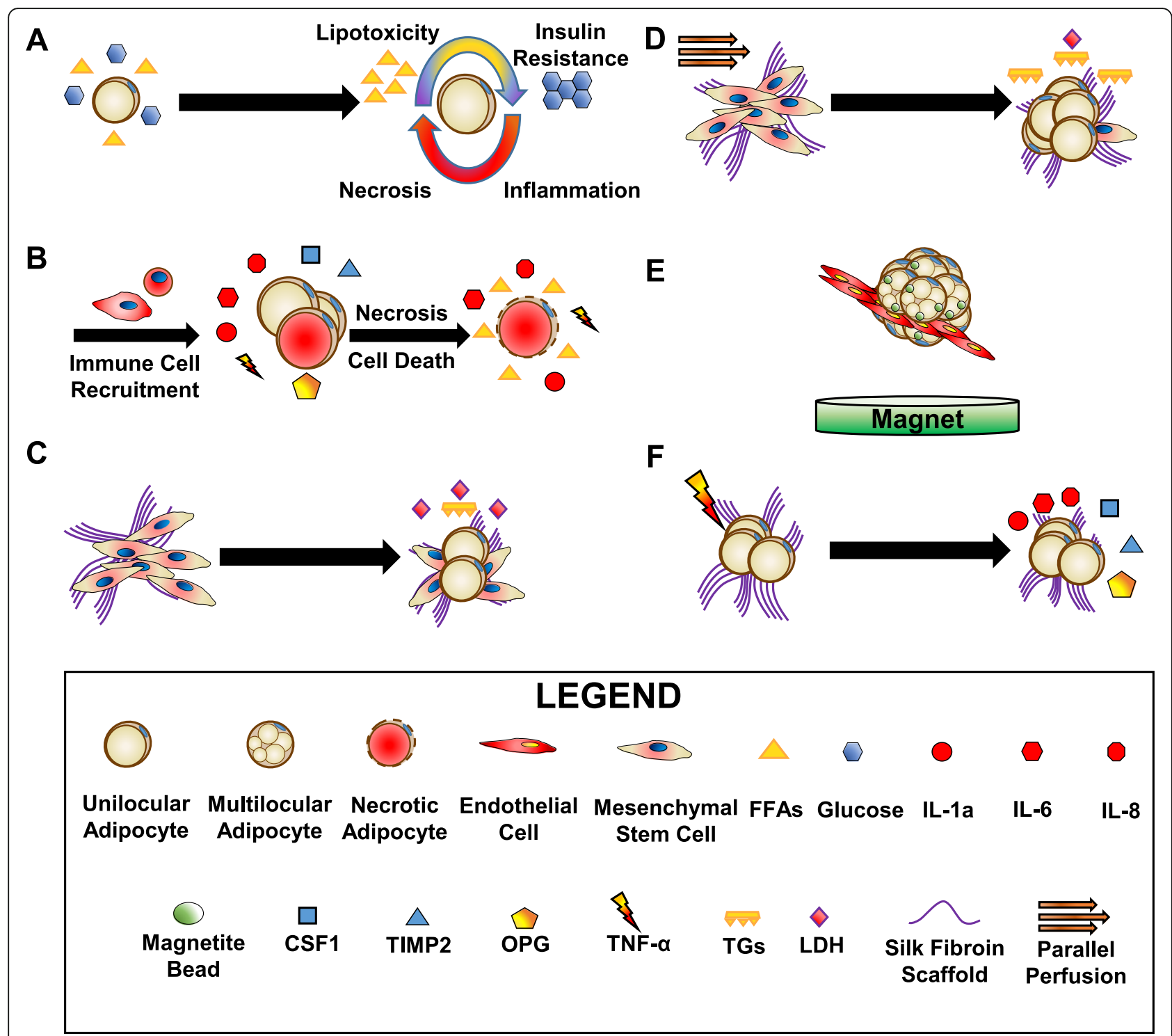

Fig. 2 Overview of the effects of obesity on adipocytes and 3D tissue-engineered adipose models of obesity. a During obesity, excess calories (whether from free fatty acids (FFAs) or glucose) cause adipocytes to become hypertrophic. The increase in FFAs causes activation of oxidative and endoplasmic reticulum (ER) stress and subsequent secretion of cytokines and adipokines. Oxidative and ER stress cause insulin resistance by negatively regulating insulin signaling. As inflammation and adipocyte size increase, oxygen is unable to penetrate the adipose tissue causing hypoxia, necrosis and eventually cell death. b Hypertrophic adipocytes secrete chemokines (C-C motif chemokine ligand 2 (CCL2), CCL8, CCL5, colony stimulating factor 1 (CSF1)) and cytokines that attract immune cells, mainly macrophages. Adipose tissue macrophages can secrete antiinflammatory factors (interleukin-10 (IL-10) and IL-1) and pro-inflammatory factors (tumor necrosis factor $a_{1}$ (TNF-a), IL-6 and IL-13). Inflammation can cause necrosis and cell death, further releasing pro-inflammatory molecules like cytokines and excess lipids, perpetuating the cycle of chronic low-grade inflammation. $\mathbf{c}$ and d Bellas et al. 2013 and Abbott et al. 2015 both demonstrated the benefits of perfusion (d, yellow-orange arrows) compared to static culture (c) for human mesenchymal stem cell (hMSC)-derived adipocytes differentiated on silk fibroin scaffolds (e.g. increased differentiation, triacylglycerols (TGs), and viable culture time, and decreased the damage-associated protein, lactate dehydrogenase (LDH)). e Daquinag et al. 2013 co-cultured 3 T3-L1 preadipocytes with the endothelial cell line bEND.3 embedded with magnetite nanoparticles. f Abbott et al. 2016 obtained adipocyte-derived stem cells from lipoaspirates and seeded and differentiated these cells on silk scaffolds. These cultures secreted factors found in both obesity (IL1-a, osteoprotegerin (OPG), and tissue inhibitor of metalloproteinases 2 (TIMP2)) and type 2 diabetes mellitus (IL-6 and IL-8)

adipocytes like adiponectin (Adipoq), fatty acid binding protein 4 (Fabp 4), and peroxisome proliferator-activated receptor gamma (Pparg). Additionally, in their 3D collagen hydrogel, visceral and subcutaneous adipose maintained distinct expression patterns in terms of thermogenesis, cytokine secretion in response to lipopolysaccharide and thermogenic and lipolysis-dependent adrenergic stimulation. Although not studying obesity 
Table 1 3D Adipose Models of Obesity, Type II Diabetes Mellitus and Cancer

\begin{tabular}{|c|c|c|c|c|}
\hline Publication & Organism & Source of Cells and Disease Context & Scaffold & Advantages over 2D / Major Findings \\
\hline $\begin{array}{l}\text { Emont et al. } 2015 \\
\text { [119] }\end{array}$ & $\begin{array}{l}\text { M. } \\
\text { musculus }\end{array}$ & $\begin{array}{l}\text { Inguinal } \\
\text { Fat Depot, } \\
\text { Perigonadal Fat Depot, SVF } \\
\text { Obesity }\end{array}$ & Collagen Hydrogel & $\begin{array}{l}\uparrow \text { Expression: } \\
\text { Adipoa } \\
\text { Fabp4 } \\
\text { Pparg } \\
\text { Distinct expression patterns } \\
\text { between inguinal and } \\
\text { perigonadal fat depots }\end{array}$ \\
\hline $\begin{array}{l}\text { Davidenko et al. } 2010 \\
\text { [120] }\end{array}$ & $\begin{array}{l}\text { M. } \\
\text { Musculus }\end{array}$ & $\begin{array}{l}\text { 3T3-L1 s } \\
\text { (pre-adipocytes) } \\
\text { Obesity }\end{array}$ & $\begin{array}{l}\text { Freeze Dried } \\
\text { Collagen-Hyaluronic Acid } \\
\text { Crosslinked with EDC and NHS }\end{array}$ & $\begin{array}{l}\uparrow 3 \text { T3-L1 Proliferation } \\
\uparrow \text { adipsin } \\
\uparrow \text { Compressive Strength and Stiffness }\end{array}$ \\
\hline $\begin{array}{l}\text { Turner et al. } 2014 \\
\text { [121] }\end{array}$ & $\begin{array}{l}\text { M. } \\
\text { Musculus }\end{array}$ & $\begin{array}{l}\text { 3T3-L1 s } \\
\text { Obesity }\end{array}$ & $\begin{array}{l}\text { Copolymer of elastin-like } \\
\text { polypeptide (ELP) and } \\
\text { polyethyleneimine (PEI) to } \\
\text { promote spheroid formation }\end{array}$ & $\begin{array}{l}\uparrow \text { Intracellular TG Content } \\
\uparrow \text { CD36 } \\
\uparrow \text { CD40 } \\
\uparrow \text { Pparg } \\
\uparrow \text { Adipoq } \\
\text { When Exposed to TNFa: } \\
\uparrow \text { Glycerol Secretion } \\
\uparrow \text { FFA Concentration in Media }\end{array}$ \\
\hline $\begin{array}{l}\text { Vidyasekar et al. } 2016 \\
\text { [122] }\end{array}$ & $\begin{array}{l}\text { M. } \\
\text { Musculus }\end{array}$ & BM-MSCs & $\begin{array}{l}\text { PLA microbeads polymerized } \\
\text { with gelatin, alginate, dextran } \\
\text { and pectin }\end{array}$ & $\begin{array}{l}\uparrow \text { Lipid Content (Nile Red) } \\
\uparrow \text { Expression: } \\
\text { Pparg } \\
\text { Fabp4 } \\
\text { Cebpa } \\
\text { Perfusion Increased above parameters }\end{array}$ \\
\hline $\begin{array}{l}\text { Kuss et al. } 2018 \\
\text { [123] }\end{array}$ & $\begin{array}{l}H . \\
\text { sapiens }\end{array}$ & $\begin{array}{l}\text { hTERT immortalized isolates } \\
\text { of BAT from a female patient } \\
\text { Obesity/T2DM }\end{array}$ & $\begin{array}{l}\text { Photocrosslinkable Hyaluronic } \\
\text { Acid and Gelatin }\end{array}$ & $\begin{array}{l}\text { Tunable Mechanical Properties } \\
\uparrow \text { Expression: } \\
\text { UCP } 1 \\
P G C 1 A \\
\text { ZIC1 } \\
\downarrow \text { Expression: } \\
\text { HDAC1 } \\
\uparrow \text { Max and Basal Respiration } \\
\downarrow \text { IL-6 } \\
\text { Improved Glucose Uptake }+/- \text { Insulin }\end{array}$ \\
\hline $\begin{array}{l}\text { Hsiao et al. } 2016 \\
\text { [124] }\end{array}$ & $\begin{array}{l}H . \\
\text { sapiens }\end{array}$ & $\begin{array}{l}\text { ASCs } \\
\text { Obesity }\end{array}$ & $\begin{array}{l}\text { collagen and fibrinogen } \\
\text { encapsulated within an } \\
\text { alginate cylindrical shell }\end{array}$ & $\begin{array}{l}\text { Unilocular Adipocytes } \\
\uparrow \text { Expression: } \\
\text { ADIPOQ }\end{array}$ \\
\hline $\begin{array}{l}\text { Mauney et al. } 2007 \\
{[125]}\end{array}$ & $\begin{array}{l}\text { H. } \\
\text { sapiens }\end{array}$ & $\begin{array}{l}\text { ASCs } \\
\text { hMSCs } \\
\text { Obesity }\end{array}$ & Silk & $\begin{array}{l}\uparrow \text { Expression: } \\
\text { FABP4 } \\
\text { PPARY } \\
\text { GLUT4 } \\
\text { ADIPSIN } \\
\text { ACS } \\
\uparrow \text { Lipid Content (Oil Red O) } \\
\text { Implantable within Mice }\end{array}$ \\
\hline $\begin{array}{l}\text { Bellas et al. } 2013 \\
\text { [126] }\end{array}$ & $\begin{array}{l}H . \\
\text { sapiens }\end{array}$ & $\begin{array}{l}\text { ASCs } \\
\text { Obesity }\end{array}$ & Silk & $\begin{array}{l}\text { Built on system in Mauney et al. } \\
\text { Dynamic Spinning } \\
\text { Increased Culture Time to } 6 \text { months }\end{array}$ \\
\hline $\begin{array}{l}\text { Abbott et al. } 2015 \\
{[127]}\end{array}$ & $\begin{array}{l}H . \\
\text { sapiens }\end{array}$ & $\begin{array}{l}\text { ASCs derived from inguinal } \\
\text { adipose tissue } \\
\text { Obesity }\end{array}$ & $\begin{array}{l}\text { Silk in a PDMS microfluidics } \\
\text { device }\end{array}$ & $\begin{array}{l}3 \mathrm{D}+\text { Perfusion: } \\
\uparrow T \text { TGs } \\
\uparrow \text { Glycerol Secretion } \\
\downarrow \text { LDH }\end{array}$ \\
\hline $\begin{array}{l}\text { Aubin et al. } 2015 \\
\text { [128] }\end{array}$ & $\begin{array}{l}H . \\
\text { sapiens }\end{array}$ & $\begin{array}{l}\text { ASCs } \\
\text { Microvascular endothelial cells } \\
\text { Obesity }\end{array}$ & $\begin{array}{l}\text { Serum and Ascorbic Acid } \\
\text { Stimulated } \\
\text { Self-assembled Cell Sheets }\end{array}$ & $\begin{array}{l}\text { Long-term culture } \\
\text { Expressed similar to AT explant: } \\
\text { Leptin } \\
\text { ANGPT1 } \\
\text { PAI-1 } \\
\text { VEGF } \\
\text { HGF } \\
\text { Mature endothelial structures }\end{array}$ \\
\hline $\begin{array}{l}\text { Aubin et al. } 2015 \\
\text { [129] }\end{array}$ & $\begin{array}{l}H . \\
\text { sapiens }\end{array}$ & $\begin{array}{l}\text { ASCs } \\
\text { Obesity }\end{array}$ & $\begin{array}{l}\text { Serum and Ascorbic Acid } \\
\text { Stimulated } \\
\text { Self-assembled Cell Sheets }\end{array}$ & $\begin{array}{l}\text { Exposure to TNF-a: } \\
\uparrow \mathrm{MCP}-1 \\
\downarrow S L C 2 A 4\end{array}$ \\
\hline
\end{tabular}


Table 1 3D Adipose Models of Obesity, Type II Diabetes Mellitus and Cancer (Continued)

\begin{tabular}{|c|c|c|c|c|}
\hline Publication & Organism & Source of Cells and Disease Context & Scaffold & Advantages over 2D / Major Findings \\
\hline & & & & $\begin{array}{l}\downarrow F A S N \\
\uparrow N F-k B-r e l a t e d \text { transcripts } \\
\text { Dynamic culture increased lipid } \\
\text { content }\end{array}$ \\
\hline $\begin{array}{l}\text { Qi et al. } 2018 \\
\text { [130] }\end{array}$ & $\begin{array}{l}H . \\
\text { sapiens }\end{array}$ & $\begin{array}{l}\text { hTERT immortalized isolates } \\
\text { of WAT from a female patient } \\
\text { and } \\
\text { HUVECs } \\
\text { Obesity }\end{array}$ & $\begin{array}{l}\text { methyacrylated HA, gelatin } \\
\text { and PEG-4A-based hydrogel }\end{array}$ & $\begin{array}{l}\uparrow \text { Expression: } \\
P P A R G \\
L P L \\
C E B P B \\
\text { Supports co-culture with endothelial } \\
\text { cells }\end{array}$ \\
\hline $\begin{array}{l}\text { Daquinag et al. } 2013 \\
\text { [131] }\end{array}$ & $\begin{array}{l}\text { M. } \\
\text { Musculus }\end{array}$ & $\begin{array}{l}\text { ASCs from the SVF } \\
3 \text { T3-L1 s } \\
\text { bEND.3 Endothelial Cells }\end{array}$ & Magnetically Levitated Cells & $\begin{array}{l}\text { Ability to form spheroids } \\
\text { Decorin Deposition }\end{array}$ \\
\hline $\begin{array}{l}\text { Choi et al. } 2010 \\
\text { [132] }\end{array}$ & $\begin{array}{l}H . \\
\text { sapiens }\end{array}$ & $\begin{array}{l}\text { ASCs } \\
\text { HUVECS } \\
\text { Obesity/ T2DM }\end{array}$ & Silk & $\begin{array}{l}\text { In co-culture w/ HUVECS and in high } \\
\text { insulin: } \\
\downarrow \text { Intracellular TG Content }\end{array}$ \\
\hline $\begin{array}{l}\text { Abbott et al. } 2016 \\
\text { [133] }\end{array}$ & $\begin{array}{l}H . \\
\text { sapiens }\end{array}$ & $\begin{array}{l}\text { Liquified Lipoaspirates: } \\
\text { Adipocytes, } \\
\text { ASCs, } \\
\text { fibroblasts, } \\
\text { smooth muscle pericytes } \\
\text { and endothelial cells } \\
\text { Obesity }\end{array}$ & Silk & $\begin{array}{l}\uparrow \text { Glycerol Secretion } \\
\uparrow \mathrm{TG} \text { Secretion } \\
\text { When Exposed to TNFa: } \\
\uparrow I \mathrm{~L} 1-a \\
\uparrow \mathrm{OPG} \\
\uparrow \mathrm{TIMP} 2 \\
\uparrow \mathrm{IL}-6 \\
\uparrow \mathrm{IL}-8 \\
\uparrow \text { RANTES }\end{array}$ \\
\hline $\begin{array}{l}\text { Das et al. } 2015 \\
\text { [134] }\end{array}$ & $\begin{array}{l}H . \\
\text { sapiens }\end{array}$ & $\begin{array}{l}\text { Adipocytes derived from } \\
\text { human nasal inferior } \\
\text { turbinate tissue-derived } \\
\text { mesenchymal stromal cells } \\
\text { Obesity }\end{array}$ & $\begin{array}{l}\text { Silk-gelatin crosslinked with } \\
\text { tyrosinase (bioink) }\end{array}$ & $\begin{array}{l}\uparrow P P A R G \\
\uparrow C E B P a \\
\uparrow L P L\end{array}$ \\
\hline $\begin{array}{l}\text { Proulx et al. } 2016 \\
\text { [135] }\end{array}$ & $\begin{array}{l}\text { H. } \\
\text { sapiens }\end{array}$ & $\begin{array}{l}\text { ASCs } \\
\text { Microvascular endothelial cells } \\
\text { Obesity }\end{array}$ & $\begin{array}{l}\text { Serum and Ascorbic Acid } \\
\text { Stimulated } \\
\text { Self-assembled Cell Sheets }\end{array}$ & $\begin{array}{l}\text { Upon adipocytes } \\
\text { stimulated with TNF- } \alpha \text { and IL- } \beta \text { : } \\
\downarrow \text { EC Length } \\
\downarrow \text { EC Branching }\end{array}$ \\
\hline $\begin{array}{l}\text { Proulx et al. } 2018 \\
\text { [136] }\end{array}$ & $\begin{array}{l}\text { H. } \\
\text { sapiens } \\
\text { M. } \\
\text { musculus }\end{array}$ & $\begin{array}{l}\text { hASCs } \\
\text { human microvascular } \\
\text { endothelial cells grafted } \\
\text { into nude mice } \\
\text { Obesity }\end{array}$ & $\begin{array}{l}\text { Serum and Ascorbic Acid } \\
\text { Stimulated } \\
\text { Self-assembled Cell Sheets }\end{array}$ & $\begin{array}{l}\text { Integrated with host vasculature } \\
\text { within } 3 \text { days } \\
\text { No significant loss of adipocyte } \\
\text { volume after } 14 \text { days of implantation. }\end{array}$ \\
\hline $\begin{array}{l}\text { Yang et al. } 2015 \\
{[137]^{*}}\end{array}$ & $\begin{array}{l}H . \\
\text { sapiens }\end{array}$ & $\begin{array}{l}\text { ASCs } \\
\text { MCF-7 s } \\
\text { Cancer }\end{array}$ & Microfluidics device & $\begin{array}{l}\text { Real-time monitoring of tissue } \\
\text { progression, Circulation-like dynamic } \\
\text { flow of media, Studying the } \\
\text { relationship between light penetration } \\
\text { and tissue depth in photodynamic } \\
\text { therapy }\end{array}$ \\
\hline $\begin{array}{l}\text { Dunn et al. } 2014 \\
\text { [138]* }\end{array}$ & $\begin{array}{l}\text { H. } \\
\text { sapiens }\end{array}$ & $\begin{array}{l}\text { Decellularized subcutaneous } \\
\text { adipose tissue from patients } \\
\text { Cancer }\end{array}$ & $\begin{array}{l}\text { Human adipose tissue derived } \\
\text { extracellular matrix }\end{array}$ & $\begin{array}{l}\text { Models ECM of Breast Cancer } \\
\text { Tumor Microenvironment }\end{array}$ \\
\hline $\begin{array}{l}\text { Campbell et al. } 2014 \\
\text { [139] }\end{array}$ & $\begin{array}{l}\text { M. } \\
\text { Musculus }\end{array}$ & $\begin{array}{l}\text { KIM-2 } \\
\text { 3 T3-L1 s } \\
\text { Cancer }\end{array}$ & Collagen/HA & $\begin{array}{l}\text { Recapitulated mammary } \\
\text { gland involution }\end{array}$ \\
\hline $\begin{array}{l}\text { Hume et al. } 2018 \text { (a) } \\
\text { [140] }\end{array}$ & $\begin{array}{l}\text { H. } \\
\text { sapiens }\end{array}$ & $\begin{array}{l}\text { MSCs } \\
\text { (isolated from mammoplasty } \\
\text { surgery) } \\
\text { MDA-MB-231 } \\
\text { Cancer }\end{array}$ & Collagen I & $\begin{array}{l}\text { Allowed: } \\
7 \text { days of co-culture of adipocytes } \\
\text { and MDA-MB-231 cells } \\
\text { Multiphoton Microscopy } \\
\text { Determination of adipocyte- } \\
\text { dependent contributions to } \\
\text { MDA-MB-231 migration }\end{array}$ \\
\hline $\begin{array}{l}\text { Hume et al. } 2018 \text { (b) } \\
\text { [141] }\end{array}$ & $\begin{array}{l}H . \\
\text { sapiens }\end{array}$ & $\begin{array}{l}\text { 3 T3-L1 s } \\
\text { MMTV-Wnt1 transgenic mouse }\end{array}$ & Collagen I & $\begin{array}{l}\text { Assess tumor fragment migration } \\
\uparrow \text { imaging capabilities due to }\end{array}$ \\
\hline
\end{tabular}


Table 13 D Adipose Models of Obesity, Type II Diabetes Mellitus and Cancer (Continued)

\begin{tabular}{|c|c|c|c|c|}
\hline Publication & Organism & Source of Cells and Disease Context & Scaffold & Advantages over 2D / Major Findings \\
\hline & & $\begin{array}{l}\text { (FVB background) } \\
\text { TUBO } \\
\text { (derived from Balb/c-Her2/neu transgenic } \\
\text { mouse) } \\
\text { Cancer }\end{array}$ & & $\begin{array}{l}\text { optical clearing } \\
\text { MMTV-Wnt1 } \\
\text { ROCK inhibitors promoted } \\
\text { MMTV-Wnt1 migration } \\
72 \mathrm{~h} \text { Adipocyte co-culture } \\
\text { was anti-migratory in MMTV-Wnt1 }\end{array}$ \\
\hline $\begin{array}{l}\text { Bougaret et al. } 2018 \\
\text { [142] }\end{array}$ & $\begin{array}{l}H . \\
\text { sapiens }\end{array}$ & $\begin{array}{l}\text { ASCs } \\
\text { MCF-7 } \\
\text { Cancer }\end{array}$ & $\begin{array}{l}\text { Collagen-glycosaminoglycan- } \\
\text { chitosan }\end{array}$ & $\begin{array}{l}\text { MCF-7 cells less sensitive to } \\
\text { the effects of tamoxifen when } \\
\text { co-cultured with adipocytes } \\
\text { from obese women } \\
\text { May be due to difference in } \\
\text { IL-6, leptin and TNFa }\end{array}$ \\
\hline $\begin{array}{l}\text { Mosaad et al. } 2018 \\
\text { [143] }\end{array}$ & $\begin{array}{l}H . \\
\text { sapiens }\end{array}$ & $\begin{array}{l}\text { Adipocytes derived from } \\
\text { BM-MSCs } \\
\text { C42Bs } \\
\text { Cancer }\end{array}$ & $\begin{array}{l}\text { Scaffold Free } \\
\text { PDMS microwell-mesh }\end{array}$ & $\begin{array}{l}\downarrow \text { of C42B cell migration in } \\
\text { co-culture with adipocytes } \\
\text { Lack of docetaxel resistance in } \\
\text { C } 42 B \text { cells co-cultured with } \\
\text { adipocytes }\end{array}$ \\
\hline $\begin{array}{l}\text { Herroon et al. } 2016 \\
{[144]}\end{array}$ & $\begin{array}{l}\text { M. } \\
\text { musculus } \\
\text { H. } \\
\text { sapiens }\end{array}$ & $\begin{array}{l}\text { Mouse Adipocytes and macrophages } \\
\text { derived from BM-MSCs } \\
\text { PC3s } \\
\text { Cancer }\end{array}$ & $\begin{array}{l}\text { Spheroids grown on Collagen } \\
\text { IV }\end{array}$ & $\begin{array}{l}\text { Adipocytes increased spheroid } \\
\text { after } 3 \text { and } 5 \text { days of co-culture }\end{array}$ \\
\hline $\begin{array}{l}\text { Fairfield et al. } 2018 \\
\text { [4] }\end{array}$ & $\begin{array}{l}\text { M. } \\
\text { Musculus } \\
\text { H. } \\
\text { sapiens }\end{array}$ & $\begin{array}{l}\text { Mouse and Human adipocytes derived } \\
\text { from BM-MSCs } \\
\text { 5TGM1 } \\
\text { (Mouse Myeloma) } \\
\text { MM1S } \\
\text { (Human Myeloma) } \\
\text { OPM2 } \\
\text { (Human Myeloma) } \\
\text { Cancer }\end{array}$ & Silk & $\begin{array}{l}\text { In Adipocytes, } \\
\text { Upregulated transcripts } \\
\text { associated with: } \\
\text { Proliferation } \\
\text { Differentiation } \\
\text { Growth Factor Response } \\
\text { ECM Secretion } \\
\text { Pattern Specification } \\
\text { In Adipocytes, } \\
\text { Downregulated Transcripts } \\
\text { associated with: } \\
\text { TLR-signaling } \\
\text { COX/COX2 Pathways } \\
\text { Lipoproteins }\end{array}$ \\
\hline
\end{tabular}

References used in the publication that pertain to 3D adipose models of obesity, type II diabetes mellitus and cancer are presented here with details regarding: organism(s) used in the study, the specific cell types and disease context, the scaffold type and major findings. Studies highlighted with an asterisk (*) do not use differentiated adipocytes. Abbreviations: 1-Ethyl-3-[3-dimethylaminopropyl] carbodiimide hydrochloride (EDC), 4arm polyethylene glycol (PEG-4A), adiponectin (ADIPOQ), adipose-derived stem cells (ASCs), Angiopoietin-1 (ANGPT1), bone marrow-derived mesenchymal stem cells (BM-MSCs), Brown adipose tissue (BAT), CCAAT enhancer binding protein alpha or beta (CEBPa or $\beta$ ), cyclooxygenase (COX), elastin-like polypeptide (ELP), extra cellular matrix (ECM), fatty acid binding protein 4 (FABP4), hepatocyte growth factor (HGF), high-density lipoproteins (HDLs), hyaluronic acid (HA), interleukin 1a (IL-1a), interleukin 1 $\beta$ (IL-1 $\beta$ ), interleukin 6 (IL-6), interleukin 8 (IL-8), interleukin 10 (IL-10), lactate dehydrogenase (LDH), lipoprotein lipase (LPL), monocyte chemoattractant protein-1 (MCP-1), mouse mammary tumor virus (MMTV), N-hydroxysuccinimide (NHS), nuclear factor kappa-light-chain-enhancer of activated B cells (NF-kB), Osteoprotegerin (OPG), peroxisome proliferator-activated receptor gamma (PPAR- $\gamma$ / Pparg), peroxisome proliferator-activated receptor gamma coactivator 1-alpha (PGC-1A), plasminogen activator inhibitor-1 (PAI-1), polydimethylsiloxane (PDMS), poly-lactic acid (PLA), regulated-on-activation-normal-T-cell-expressed-and-secreted (RANTES), rho associated coiled-coil containing protein kinase (ROCK), stromal vascular fraction (SVF), three-dimensional (3D), toll-like receptors (TLR), Triacylglycerols (TGs), tumor necrosis factor alpha (TNF-a), two-dimensional (2D), type 2 diabetes mellitus (T2DM), uncoupling protein 1 (UCP1), vascular endothelial growth factor (VEGF), white adipose tissue (WAT)

directly, this 3D collagen-based method could be utilized to model obesity, T2DM, and other adipose-related diseases.

Davidenko et al. characterized the physical properties of a collagen-hyaluronic acid (HA)-based 3D scaffold. Collagen and HA mixtures were made with 7.5 and 15\% HA, freeze-dried, and subsequently crosslinked with 1Ethyl-3-[3-dimethylaminopropyl] carbodiimide hydrochloride (EDC) and N-hydroxysuccinimide (NHS), which facilitates the attachment of glycosaminoglycans (GAGs) to collagen and provides structural support to the scaffold [120]. When compared to collagen scaffolds alone, they found that the pore size ranged from 100 to
$220 \mu \mathrm{m}$, had a similar degradation time, and had increased compressive strength and stiffness. The collagen-HA scaffolds also increased the proliferation of mouse adipocyte precursors (3 T3-L1 s) and increased expression of the adipokine, complement factor $D$ (adipsin), although Pparg expression was not significantly changed. The determination of the total number of cells, lipid content, insulin signaling, metabolism, and thermogenic capacity of adipose tissue would help solidify this approach as a viable disease model.

In an effort to assess the inflammatory capacity of adipose tissue in a 3D environment, Turner et al. used a copolymer of elastin-like polypeptide (ELP) and 
polyethyleneimine (PEI) to promote adipocyte spheroid formation [121]. Turner and colleagues showed that differentiated mouse 3T3L-1 spheroids had increased intracellular TG and increased protein expression of the fatty acid uptake regulator CD36, CD40, Pparg, and Adipoq when compared to $2 \mathrm{D}$ cell culture. Upon stimulation with TNF- $\alpha$, there was an increase in both glycerol secretion and concentration of FFAs, indicative of lipolysis. Follow-up proteomics and confirmation of lipolysis would help confirm the ability of researchers to model obesity-related inflammation. While both Turner et al. and Emont et al. analyzed the inflammatory capacities of adipose tissue in their respective 3D models, researchers must be aware that the inflammatory signaling (particularly TNF and beta-3 adrenergic receptor signaling) differ between mice and humans [119, 121, 145-147]. Studies centered on the inflammatory response of current human models are reviewed in the proceeding sections.

Vidyasekar et al. used poly-lactic acid (PLA) microbeads polymerized with gelatin, alginate, dextran, and pectin as a scaffold for mouse bone marrow-derived MSCs (BM-MSCs) to test whether functional pre-adipocytes could differentiate on this substrate [122]. Indeed, the microbeads supported adipogenesis as shown by an increase in Nile Red staining and the upregulation of Pparg, Fabp4, and Cebpo. These parameters were further enhanced by culturing the microbead-associated cells in a rotating container, further supporting the benefits of mechanical forces and perfusion to recapitulate the in vivo environment.

\section{Human avascular 3D adipose disease models}

While the majority of 3D adipose tissue models primarily focus on WAT, Kuss et al. aimed to engineer a photocrosslinkable HA and gelatin-based 3D BAT model to explore the role of brown adipose depots in obesity and T2DM [123]. The authors used bioprinted photocrosslinkable methacrylate to alter both the porosity and stiffness of their scaffolds based on varying the spacing parameters during printing and exposure to ultraviolet light, respectively. The authors showed that immortalized brown adipocytes cultured with angiogenic factors such as vascular endothelial growth factor (VEGF) and fibroblast growth factor 2 (FGF2) before differentiation showed an enhanced brown adipose phenotype by significant upregulation of Ucp1, Pgc1 1 , and Zic1 and a concurrent decrease of a negative regulator of BAT differentiation, Hdac1. Immortalized BAT cell lines seeded onto stiff and porous scaffolds showed increased BAT gene expression, basal and maximal respiration, decreased inflammatory markers such as IL-6, and improved glucose uptake in the presence and absence of insulin. Taken together, Kuss et al. demonstrated that the use of methacrylated HA and gelatin supports culturing brown adipocytes and their metabolic activity, and they found that expression patterns can be modulated by modifying the porosity and stiffness of the matrix. This phototunable model allows the possibility of spatial specific differentiation of MSCs into adipocytes, offering the possibility to study the interactions of WAT, BAT, and other cell types on one contiguous scaffold.

On the other hand, Hsiao et al. engineered a flexible corkscrew-shaped model of 3D adipose tissue by seeding human adipose-derived stem cells (ASCs) into collagen and fibrinogen encapsulated within an alginate cylindrical shell [124]. Upon the addition of adipogenic media, clear unilocular adipocytes were observed and an increase in ADIPOQ after 11 days was evident. Additional molecular markers of adipose tissue differentiation and obesity would help determine if this physically flexible model could be used to study adipose-related diseases. The presence of the alginate shell in this model offers the possibility to study the contributions of paracrine and juxtracrine signals of adipocytes on any cell type of interest in vitro and in vivo as an implant.

The Kaplan group was the first to use silk 3D scaffolds as model for tissue-engineered adipose tissue in 2007 [125]. Mauney et al. assessed adipogenesis in four different scaffold biomaterials: silk prepared by aqueous and organic solvent-based processes, collagen, and PLA. Human ASCs (hASCs) and human bone marrow-MSCs (hBM-MSCs) seeded onto silk scaffolds and allowed to differentiate into adipocytes showed expression of genes associated with adipocyte differentiation: FABP4, PPAR , GLUT4, adipsin, and acyl-CoA synthetase and had accumulated lipids as measured by Oil Red O. In order to demonstrate a clinical application of this approach, silk scaffolds seeded with either ASCs and BM-MSCs that were implanted into mice were able to undergo adipogenesis and were more durable than both the collagen and PLA-based scaffolds. In 2013, Bellas et al. showed that the addition of dynamic spinning turbulence during culture of adipose tissue seeded onto the silk scaffolds described by Mauney et al. could support functional adipocytes for up to 6 months (Fig. 2c,d) [125, 126].

Abbott et al. then developed a parallel perfusion method that utilized a 3D silk scaffold embedded in a polydimethylsiloxane (PDMS) device that had channels that allowed longitudinal flow of liquid across the scaffold (Fig. 2c,d) [127]. Adipocytes cultured on the 3D scaffold under perfusion had increased TGs and glycerol secretion and had a remarkable reduction in the damage associated protein, lactate dehydrogenase (LDH), after 42 days of culture compared to 2D cell culture. Both Bellas et al. and Abbott et al. demonstrate that the addition of dynamic flow to silk scaffolds can functionally improve adipose tissue and increase the longevity of 
cultures $[126,127]$. The long-term culture that silk scaffolds afford offers researchers to gain deeper insight into the progression of adipose-related diseases but is not limited to silk scaffolds.

Interestingly, in a self-assembly cell sheet-based 3D model, Aubin et al. demonstrated healthy culturing of adipocytes to at least 81 days after differentiation [128]. Briefly, human ASCs derived from lipoaspirates were seeded onto paper anchorage discs and induced to deposit their ECM via the addition of serum and ascorbic acid $[128,129]$. The cell sheets were stacked on top of one another to the desired tissue thickness. Adipocytes cultured in this model expressed leptin, angiopoietin-1 (ANGPT1), plasminogen activator inhibitor-1 (PAI-1), VEGF, and hepatocyte growth factor (HGF) to similar levels as patient explants [128]. Importantly, Aubin et al. also showed a physiological relevant response to TNF- $\alpha$ stimulation in terms of monocyte chemoattractant protein-1 (MCP-1) expression, downregulation of genes involved in insulin-mediated uptake of glucose and fatty acid synthesis, as well as increased expression in NF-kBrelated transcripts [128]. Finally, self-assembled adipose sheets in dynamic culture had increased lipid content as seen by Oil Red $O$ staining after 7, 14, and 21 days after differentiation. Taken together, the model developed by Aubin et al. offers a model to study the inflammatory response of adipocytes and its effect on other cell types over a period of months.

While the addition of dynamic flow may serve the function of increasing nutrient availability like the vasculature, the addition of endothelial cells more accurately models the in vivo microenvironment in terms of cellto-cell interactions.

\section{Human vascular 3D adipose disease models}

In a complementary study to Kuss et al., the Duan group engineered a methacrylated HA, gelatin, and 4arm polyethylene glycol (PEG-4A)-based hydrogel using cryopolymerization, where controlled freeze-thaw cycles led to enhanced tensile strength and a microporous network. As opposed to traditional hydrogels, the Duan design enables injections of media or reagents multiple times $[130,148]$. This cryogel model increased the expression of adipocyte-related genes such as PPARG, lipoprotein lipase $(L P L)$, and CCAAT Enhancer Binding Protein Beta $(C E B P B)$ in a differentiated human immortalized white adipose cell line. The expression of these genes was further enhanced by co-culture of human umbilical vascular endothelial cells (HUVECs). As opposed to the stiff porous scaffold described in Kuss et al., the flexible and porous cryogel method supported the culture of WAT cells with and without other cell types $[123,130]$.

Daquinag et al. adapted a technique developed by the Pasqualini lab which used a magnetite and gold nanoparticles crosslinked to poly-L lysine to promote endocytosis to magnetically suspend scaffolds and promote 3D spheroid formation (Fig. 2e) [131, 149]. The scaffolds were seeded with ASCs from the stromal vascular fraction (SVF) or the pre-adipocyte mouse cell line, 3 T3-L1, and allowed to differentiate into WAT while being magnetically suspended. The magneticallylevitated scaffolds demonstrated the ability to form a spherical complex with mature adipocytes, $\mathrm{CD}^{+} 1^{+}$endothelial cells, and the deposition of the ECM protein, decorin. It will be exciting to see how the magneticallylevitated cells are functionally different when compared to both 2D and other 3D adipose models.

Choi et al. aimed to model insulin resistance in a adipocyte and endothelial cell co-culture model on the silk scaffolds described in Mauney et al. [125, 132]. hASCs were plated in $3 \mathrm{D}$ mono or co-culture with endothelial cells in the presence of $1 \mu \mathrm{M}$ or $10 \mu \mathrm{M}$ insulin. When exposed to high concentrations of insulin $(10 \mu \mathrm{M})$, cocultured adipocytes showed decreased intracellular TG content after 9 days, suggesting increased lipolysis, a physiological trend observed in obesity and in T2DM. Adipocyte cultures alone and those exposed to high insulin concentrations however, did not show changes in TG content or lipolysis, suggesting that that endothelial cells may be important for producing more physiologically-relevant adipose models for studying obesity or T2DM.

In a similar model, Abbott et al. seeded liquified human lipoaspirates onto 3D silk scaffolds and determined adipocytes have increased glycerol and TG secretion compared to 2D culture [133]. In order to model the low-grade inflammation observed in obesity, the secretome of adipocytes exposed to TNF $\alpha$ in $2 \mathrm{D}$ and 3D culture was assessed (Fig. 2f) [133]. Interestingly, when treated with the pro-inflammatory cytokine, TNF $\alpha$, adipocytes grown on 3D scaffolds secreted obesityassociated markers such as: IL1- $\alpha$, osteoprotegerin (OPG), tissue inhibitor of metalloproteinases 2 (TIMP2), as well as T2DM related proteins such as IL-6, IL-8, and regulated-on-activation-normal-T-Cell-expressed-andsecreted (RANTES) [133]. In contrast to expectations and also the work by Aubin et al., TNF- $\alpha$ stimulation increased glucose uptake which the authors attribute to other cell types within the lipoaspirates, including endothelial cells $[128,150]$. These data demonstrate that adipocytes grown on a silk scaffold and subject to acute inflammation, respond in a similar manner as to what is observed in obesity and T2DM but the interactions between adipocytes and other cell types in the microenvironment are responsible for the full phenotype seen in patients.

Silk fibroin has also been used in a hydrogel format to bioprint scaffolds to support the differentiation of 
chondrocytes, osteocytes, and adipose tissue [134]. Das et al. showed that silk fibroin hydrogels bioprinted and crosslinked with tyrosinase supported the expression of $P P A R G, C E B P \alpha$, and $L P L$ in adipocytes derived from human nasal inferior turbinate tissue-derived mesenchymal stromal cells. Because Das et al. focused on chondrogenesis and osteogenesis, the morphology and function of adipocytes differentiated on this matrix are unclear. It would be interesting to see how their method directly compares to other solid silk scaffold and hydrogel-based models.

The above models primarily focused on adipocyte biology with and without endothelial cells. However, in 2016, Proulx et al. analyzed the influence of adipocytes exposed to TNF and IL-1 $\beta$ on endothelial cells derived from human microvascular endothelial cells using the model established by Aubin et al. [129, 135]. Intriguingly, capillary-like structures made of endothelial cells exposed to TNF- $\alpha$ or IL- $1 \beta$ were shorter, less branched and were more apoptotic; demonstrating a valid model to study the crosstalk between adipocytes and endothelial cells. Indeed, a follow-up study by Proulx et al. in 2018 implanted these models in nude mice for 14 days and found that the human endothelial cells integrated with the host vasculature within 3 days [136]. Proulx et al. and the aforementioned models provide crucial insights into the complexity associated with obesity and T2DM that 1 day may be translated into the clinic.

\section{Cancer}

As researchers learn more about the contributions of obesity and adipose tissue to cancer progression, tissueengineered adipose models are becoming increasingly useful and necessary to interrogate the interactions between cancer cells and adipose tissues. (For more on 3D tissue-engineered in vitro models of cancer in bone, please see previous reviews $[5,151]$.) In designing 3D adipose-cancer models, researchers must consider parameters such as: cell type/source, concentration, and ratios; scaffold material properties and pore size; media composition; imaging modalities desired; and potential bioreactor or other influences of stress or strain on the model. Interestingly, it appears that gravitational forces can also affect differentiation of BM-MSCs into osteogenic or adipogenic lineages, so this may be another parameter that could be altered, if necessary [152].

The most common 3D adipose/cancer models that have been developed are used to study breast cancer, although a few models have also been developed to study adipocyte-prostate cancer cell interactions and bone marrow adipocyte-myeloma cell interactions. These model systems will be described here.
For a review of synthetic adipose model systems for breast tissue engineering applications developed before 2010, please see the following review [153]. Since 2010, there have been substantial advances in model systems, and in 2014 a model was even developed to recapitulate mammary gland involution using engineered porous collagen/HA matrices [139]. This study used a mouse mammary epithelial cell line (KIM-2) and mouse 3 T3L1 pre-adipocytes that were differentiated into adipocytes. This model could easily be adapted to study carcinogenesis.

One 3D model that has been used to study breast cancer is a microfluidic system with human breast cancer cells (MCF-7) and primary ASCs, although these were not differentiated into adipocytes (though the possibility exists). The model system was the first to demonstrate the potential use of a microfluidic-based in vitro 3D breast cancer model for effective evaluation of photodynamic therapy [137]. Their highly controllable model had the capability for real-time monitoring of tissue progression, implementing a circulation-like dynamic flow of media, drug testing and investigating the relationship between light penetration and tissue depth in photodynamic therapy [137]. This highly innovative model may be used to study adipocyte-breast cancer cell interactions in future work. The 3D nature of this model was a result of the chamber depth $(200 \mu \mathrm{m})$, which allowed the stromal and cancer cells to produce their own ECM by self-organization, although the components of this ECM were not characterized in this study.

Another useful 3D model system is the human decellularized adipose tissue scaffold, which has been used to model breast cancer growth and drug response in vitro [138]. The benefit of these models is that they have similar ECM composition to the microenvironment of human breast tissue and recapitulate in vivo results much more closely than 2D models can, but they do not include live adipocytes currently [138]. An easy next step would be co-culturing adipocytes with breast cancer cells in these models. Similarly, silk scaffolds have been used to culture breast cancer cells in a 3D microenvironment [154]. Although no breast cancer and adipocyte co-cultures on silk have been described, many adipose tissue silk cultures have been described (see above) and thus silk scaffold adipose and silk scaffold breast cancer cell models could easily be combined to form breast cancer/adipocyte co-cultures on silk matrices.

In 2018, Hume et al. described a model using engineered collagen I scaffolds seeded with hMSCs that were differentiated into mature adipocytes [140]. The model supported co-culture with the breast cancer cell line MDA-MB-231, for 7 days and allowed for multiphoton microscopy analysis. Greater migration of cancer cells was observed in adipose-containing models versus 
empty, control scaffolds, demonstrating their utility in examining adipocyte contributions to tumor cell homing or metastasis. This model was then built upon to study tumor fragment cultures by the same group [141]. This model was used to distinguish tumor cell migration phenotypes and to test therapeutic agents for their effect on tumor cell migration. Clear, unobstructed brain/body imaging cocktails and computational analysis (CUBIC) optical clearing methods were utilized to make the samples optically transparent so that the responses of tumor cells could be more easily assessed. These exciting models may be used to explore even more about adipocyte-tumor cell crosstalk in future studies.

A new model using collagen-glycosaminoglycanchitosan scaffolds and mature adipocytes differentiated from hASCs was developed in 2018 [142]. The investigators found that MCF-7 breast cancer cells were less sensitive to the anti-proliferative effects of tamoxifen when co-cultured with adipocytes derived from obese rather than normal-BMI women. These results suggested the tamoxifen resistance is in part due to differences in IL-6, leptin, and TNF $\alpha$ between adipose from leaner and obese women's hASCs [142]. This interesting finding highlights the utility of new models to bring new insights into the ways in which adipocytes and tumor cells interact and the role of obesity in altering that relationship. This work was based on a previous publication from 2013 where the fatty-tissue equivalent was developed, breast cancer cells were found to change the process of adipogenesis, and many genes were differentially expressed by breast cancer cells when cultured with adipose models versus controls [155]. These publications have thus revealed the numerous ways in which adipocytes and tumor cells partake in crosstalk and bidirectional signaling.

In addition to breast cancer, prostate cancer-adipocyte $3 \mathrm{D}$ and myeloma cell-adipocyte models have also been developed. In 2018, Mosaad et al. published a highthroughput microtissue culture system where 3D cultures were formed using a novel microwell platform, the Microwell-mesh [143]. Adipocytes were differentiated from $h M S C s$ and added to firefly luciferase-expressing C42B prostate cancer cells to create scaffold-free $3 \mathrm{D} \mathrm{cul-}$ tures, or tumor cells were cultured above the adipocytes in a transwell and assessed for migration. Interestingly, 3D adipocyte cultures decreased prostate cancer cell chemotaxis significantly, while $2 \mathrm{D}$ adipocyte cultures induced a slight increase in PC3 prostate cancer cell chemotaxis, highlighting the differences in secreted factors from 2D and 3D adipocytes [143]. Also, docetaxel drug resistance was seen in C42B prostate cancer cells when cultured in 2D with hMSCs or adipocytes, but drug resistance was not seen with adipocytes when cultured in 3D, as assessed by bioluminescence [143]. In another model of prostate cancer from the Podgorski laboratory, prostate tumor spheroids were grown on reconstituted basement membranes and cultured alone or in transwell with bone marrow adipocytes [144]. The adipocytes increased the prostate tumor spheroid after 3 and 5 days in co-culture. The group also included bone marrow macrophages into some of their 3D hydrogel cultures and used the models to study prostate cancer cell response to therapies and migration patterns [144]. Our laboratory has developed a 3D BMAT model that uses silk scaffolds, adipocytes derived from mouse or human BM-MSCs, and multiple myeloma (MM) cell lines (Fig. 3a and b) $[4,156]$. By comparing 2D to 3D culture, we observed that 3D BMAT was much more physiologically relevant than 2D BMAT. Microarray analysis of MSCs differentiated for 28 days on 3D silk scaffolds revealed that pathways such as DNA replication, ribosome biosynthesis, cell cycle, and metabolic pathways were significantly enriched relative to 2D culture [4]. Conversely, pathways related to inflammation (NOD-like receptor), disease (malaria and prion-related diseases), and cytokines (TNF) were significantly enriched in 2D BMAT. Parallel proteomic analysis revealed similar patterns as the microarray data [4]. Given the intimate link between inflammation and obesity, T2DM and cancer, the perception of healthy control AT in traditional 2D cell culture may be closer phenotypically to the inflammatory disease phenotypes that are being studied. The use of our 3D silk model and other models like it will allow a more refined definition of "healthy" and diseasestate adipose tissue. We also observed that adipocytes supported MM cell growth and that MM cells induced delipidation of BM adipocytes, through processes that are as of yet unknown but that we are investigating [4]. Overall, by using 3D models of prostate, breast, or myeloma cancer cells and adipocytes, researchers have elucidated new mechanisms of tumor-host interaction, which represent important and useful research directions to pursue.

\section{Conclusions}

Herein, we reviewed the efforts of researchers across varying disciplines to recapitulate the complex picture of adipocytes in their natural environment using $3 \mathrm{D}$ bioengineered environments. Human and mouse precursors plumped up as they expressed PPAR- $\gamma$, adiponectin, FABP4, and leptin on a diverse array of materials ranging from collagen, silk, and even to magnetically levitated spheres. The addition of perfusion further improved upon the phenotype of adipocytes reflecting their in vivo counterparts. To a degree, the behavior of adipocytes on 3D silk scaffolds recapitulated the hyperinsulinism that is observed in obese patients. Additionally, hydrogel, silk-based and scaffold-free co-culture experiments with adipocytes highlighted the supportive 

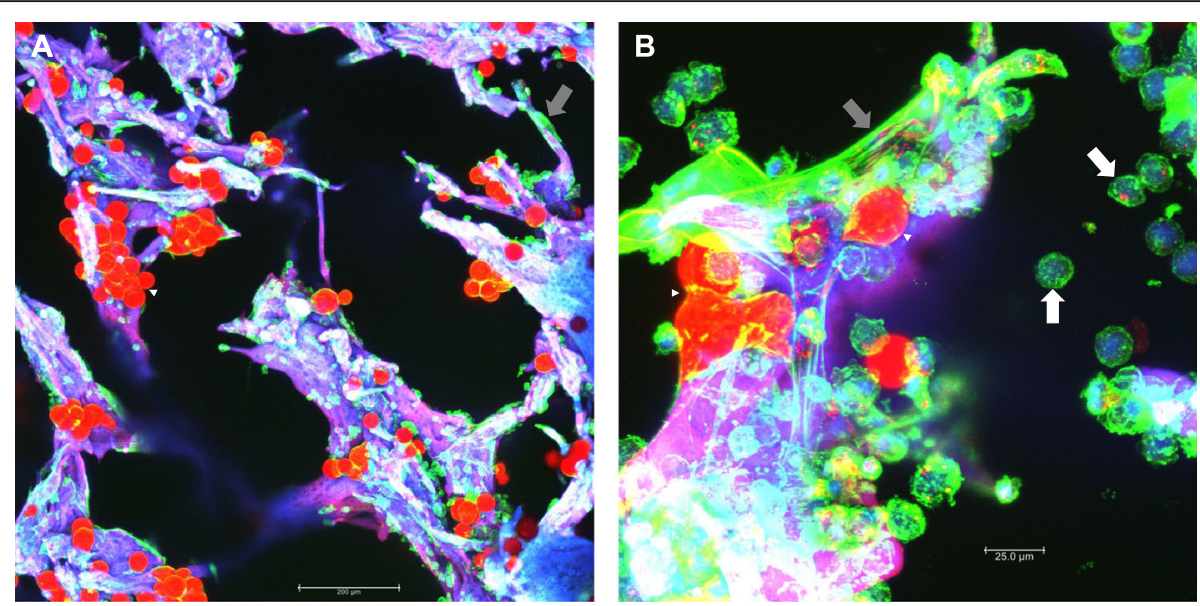

Fig. 3 Example of tissue-engineered bone marrow adipose tissue. Silk scaffolds were used as a platform to make 3D, tissue-engineered bone marrow adipose tissue (BMAT). a Mouse BMAT was differentiated from male, 10-month-old KaLwRij mouse-derived bone marrow mesenchymal stem cells (BM-MSCs). Briefly, BM-MSCs were seeded onto scaffolds and cultured for 6 days, then put into adipogenic media for 10 days, put into a maintenance media for 1 week, and finally imaged. Scale bar $=200 \mu \mathrm{m}$. b Mouse-derived BM-MSCs were treated as above up until adipogenesis then the mouse myeloma cell line, 5TGM1s, were co-culture with the differentiated adipocytes for 1 week in maintenance media. Scale bar $=25.0 \mu \mathrm{m}$. Samples were stained Oil Red $\mathrm{O}$ (red) and phalloidin/actin (green). The scaffolds are autofluorescent in all channels and thus appear purple. Imaging was performed with a confocal microscope using maximum projections of Z-stacked images. Many adipocytes are visible (red, white arrowheads), along with many undifferentiated stromal cells (grey arrows). Rounded green myeloma cells are seen throughout the scaffold (white arrows)

role endothelial cells have in reflecting the in vivo environment and pave the way for modeling PVAT. With "omics" technology being more accessible, it has now been applied to the tissue engineering field to identify global expression and secretomes of adipose tissue on various types of scaffolds. These techniques have also been applied to co-culture experiments with adipocytes and various types of cancer to elucidate the bidirectional effects of each cell type. Modeling BAT on a photocrosslinkable hyaluronic acid-based scaffold proved to be a promising effort to explore the role of BAT in obesity and beyond. It may be interesting to use scaffolds in conjunction with a technique by the Brown lab, which used induced pluripotent stem cells to generate a renewable source of beige adipocytes [157]. One could imagine growing and implanting these cells to treat patients with metabolic disorders. The use of 3D models could also be applied to studying lipodystrophies associated with certain pharmaceuticals, genetic conditions, human immunodeficiency, viral infections, and beyond [158]. While great strides have been made in the tissueengineered adipose field, exploration into immune cell recruitment to hypertrophic adipocytes, the status of hypoxia signaling within modeled tissue, and the effects of other engineered tissues like the pancreas, may create a more holistic disease model for obesity and T2DM.

The majority of 3D models that analyze interactions between cancer cells and adipocytes focus on breast cancer, prostate cancer, and myeloma. These models lay down a foundation for investigating other canceradipocyte interactions like melanoma, acute myeloid leukemia, lipomas, and ovarian cancer. Additionally, cancer-associated cachexia could be studied in vitro via co-culture experiments with adipocytes, cancer cells, muscle cells, and other cell types of the researcher's choice. 3D scaffolds offer an alternative to time and resource intensive animal models and have the potential for high-throughput analyses. Based on the literature reviewed here, the horizon of tissue-engineered adipose models is bright and will grow to meet the everincreasing demand to understand and treat diseases like obesity, T2DM, and cancer.

\section{Abbreviations}

2D: Two-dimensional; 3D: Three-dimensional; ACC: Acetyl-CoA carboxylase; ACS: Acyl-CoA synthetase; ADIPOQ: Adiponectin; ANGPT1: Angiopoietin-1; ApoE: Apolipoprotein E; ATMs: Adipose tissue macrophages; ATP: Adenosine triphosphate; BAT: Brown adipose tissue; BMAT: Bone marrow adipose tissue; BMI: Body mass index; BM-MSCs: Bone marrow-derived mesenchymal stem cells; CCL: C-C motif chemokine ligand; CCR: Chemokine receptor;

CEBPB: CCAAT Enhancer Binding Protein Beta; CUBIC: Clear, unobstructed brain/body imaging cocktails and computational analysis;

DHT: Dihydrotestosterone; Dio2: Type 2 deiodinase; EDC: 1-Ethyl-3-[3dimethylaminopropyl] carbodiimide hydrochloride; ELP: Elastin-like

polypeptide; ER: Endoplasmic Reticulum; FABP4: Fatty acid binding protein 4; FFAs: Free fatty acids; FGF2: Fibroblast growth factor 2;

GAGs: Glycosaminoglycans; HA: Hyaluronic acid; hASCs: Human adiposederived stem cells; hBM-MSCs: Human bone marrow-derived mesenchymal stem cells; HDLs: High-density lipoproteins; HGF: Hepatocyte growth factor; IKK- $\beta$ : I kappa B kinase beta; IL-10: Interleukin 10; IL-1 a: Interleukin 1a; IL-

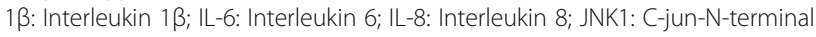
kinase; LD: Lipid droplet; LDH: Lactate dehydrogenase; LPL: Lipoprotein lipase; MAPK: Mitogen activated protein kinase; MCP-1: Monocyte chemoattractant protein-1; NFkB: Nuclear factor kappa-light-chain-enhancer of activated B cells; NHS: N-hydroxysuccinimide; OPG: Osteoprotegerin; PAl1: Plasminogen activator inhibitor-1; PDMS: Polydimethylsiloxane; PEG4A: 4arm polyethylene glycol; PET-CT: Positron-emission tomography and computed tomography; PGC-1a: Peroxisome proliferator-activated receptor 
gamma coactivator 1-alpha; PI3K: Phosphatidylinositol 3-kinase; PKA: Protein kinase A; PLA: Poly-lactic acid; PEl: Polyethyleneimine; PPAR-y: Peroxisome proliferator-activated receptor gamma; PRDM16: PR domain containing 16; PVAT: Perivascular adipose tissue; RANTES: Regulated-on-activation-normal-TCell-expressed-and-secreted; SAT: Subcutaneous adipose tissue; SVF: Stromal vascular fraction; T2DM: Type 2 diabetes mellitus; TGs: Triacylglycerols; TIMP2: Tissue inhibitor of metalloproteinases 2; TNF-a: Tumor necrosis factor alpha; UCP1: Uncoupling protein 1; VAT: Visceral adipose tissue; VEGF: Vascular endothelial growth factor; WAT: White adipose tissue

\section{Acknowledgements}

We would like to thank all members of the Reagan lab, Calvin Vary Joel Miller and CVM for assistance in discussing the review and supporting our work. Permission was obtained to acknowledge each individual listed in the acknowledgements section.

\section{Authors' contributions}

CSM, LL, and MRR wrote, edited, and provided final approval of the manuscript. LL made Fig. 1, CSM made Fig. 2, and CSM and MRR made Fig. 3 in the manuscript. MRR provided funding for the manuscript.

\section{Funding}

Support was from the NIH's National Institute of General Medical Science from: the Phase I COBRE in Metabolic Networks (P20GM121301), and Histology core support from NIH P30 GM106391, P20GM121301, U54GM115516. The authors' work is supported by an American Cancer Society Research Grant \#IRG-16-191-33, the NIH/NIDDK (R24 DK092759-01), a grant from the Kane Foundation, a pilot from Harvard's Skeletal Phenotyping Core (NIH/NIAMS P30 AR066261), and start-up funds from the Maine Medical Center Research Institute. The Reagan laboratory was supported by a contract with Union Chemique Belge. The above funding sources supported the salaries of CSM, LL and MRR but did not have any role in the design of the study and collection, analysis, and interpretation of data or in writing the manuscript.

\section{Availability of data and materials}

Data sharing not applicable to this article as no datasets were generated or analyzed during the current study.

\section{Ethics approval and consent to participate}

The data reproduced from Boucher et al. 2018 (Boucher JM, Robich M, Scott SS, Yang X, Ryzhova L, Turner JE, Pinz I, Liaw L. Rab27a regulates human perivascular adipose progenitor cell differentiation. Cardiovascular Drugs and Therapy: PVAT Biology 2018, 32(5):519-530) utilized human tissue that was procured via our Maine Medical Center Biobank, which provides deidentified samples. This study was reviewed and deemed exempt by our Maine Medical Center Institutional Review Board. The BioBank protocols are in accordance with the ethical standards of our institution and with the 1964 Helsinki declaration and its later amendments or comparable ethical standards. Informed consent was obtained from all individuals for de-identified use of their samples for research purposes. Consent to reproduce data from Boucher et al. 2018 in this review was obtained from Springer Nature and the senior author of the paper, Dr. Lucy Liaw. The data from Fig. 1d was reprinted by permission from RightsLink: Springer Nature, Cardiovascular Drugs and Therapy, Boucher et al. 2018

\section{Consent for publication}

Not applicable.

\section{Competing interests}

The Reagan laboratory was also supported by Union Chemique Belge, but that contractual funding had no effect on the content within this review article. The Liaw lab (senior author of Boucher et al. 2018) did not receive funding from Union Chemique Belge or other funding sources that would warrant the declaration of a competing interest.

\section{Author details}

${ }^{1}$ Maine Medical Center Research Institute, Scarborough, ME, USA. ${ }^{2}$ University of Maine Graduate School of Biomedical Science and Engineering, Orono, ME, USA. ${ }^{3}$ School of Medicine, Tufts University, Boston, MA, USA. ${ }^{4}$ Center for
Molecular Medicine and Center for Translational Research, 81 Research Drive, Scarborough, ME 04074, USA.

Received: 1 April 2019 Accepted: 16 September 2019

Published online: 29 October 2019

\section{References}

1. Mullard A. Parsing clinical success rates. Nat Publ Gr. 2016;15:447. https://doi. org/10.1038/nrd.2016.136

2. Dimasi JA, Grabowski HG, Hansen RW. Innovation in the pharmaceutical industry : new estimates of R \& D costs. J Health Econ. 2016;47:20-33. https://doi.org/10.1016/j.jhealeco.2016.01.012.

3. Lee J, Cuddihy MJ, Kotov NA. Three-dimensional cell culture matrices : state of the art. Tissue Eng Part B Rev. 2008;14. https:/doi.org/10.1089/teb.2007.0150.

4. Fairfield H, Falank C, Farrell M, Vary C, Boucher JM, Driscoll H, et al. Development of a 3D bone marrow adipose tissue model. Bone. 2019;118: 77-88. https://doi.org/10.1016/j.bone.2018.01.023.

5. Sitarski AM, Fairfield H, Falank C, Reagan MR. 3D tissue engineered in vitro models of Cancer in bone. ACS Biomater Sci Eng. 2017;2:324-36. https://doi. org/10.1021/acsbiomaterials.7b00097.

6. Brett E, Chung N, Leavitt WT, Momeni A, Longaker MT, Wan DC. A review of cell-based strategies for soft tissue reconstruction. Tissue Eng Part B Rev. 2017;23:336-46. https://doi.org/10.1089/ten. TEB.2016.0455.

7. Mahoney CM, Imbarlina C, Yates CC, Marra KG. Current therapeutic strategies for adipose tissue defects/repair using engineered biomaterials and biomolecule formulations. Front Pharmacol. 2018;9:1-12. https://doi. org/10.3389/fphar.2018.00507.

8. Kaplan DL, Vunjak-Novakovic G, Yoo JJ, Lee K, Marra KG, Gimble JM, et al. Adipose tissue engineering for soft tissue regeneration. Tissue Eng Part B Rev. 2010;16:413-26. https://doi.org/10.1089/ten. TEB.2009.0544.

9. Rosen ED, Spiegelman BM. What we talk about when we talk about fat. Cell. 2014;156:20-44. https://doi.org/10.1016/j.cell.2013.12.012.

10. Kozak LP, Koza RA. The Genetics of Brown Adipose Tissue. In: Bouchard CBT$P$ in MB and TS. Genes and Obesity. London: Academic Press; 2010. p. $75-$ 123. https://doi.org/10.1016/B978-0-12-375003-7.00004-2.

11. Giralt M, Villarroya F. White, brown, beige/brite: different adipose cells for different functions? Endocrinology. 2013;154:2992-3000. https://doi.org/10. 1210/en.2013-1403.

12. Horowitz MC, Berry R, Holtrup B, Sebo Z, Nelson T, Fretz JA, et al. Bone marrow adipocytes. Adipocyte. 2017;6:193-204. https://doi.org/10.1080/ 21623945.2017.1367881.

13. Costa RM, Neves KB, Tostes RC, Lobato NS. Perivascular adipose tissue as a relevant fat depot for cardiovascular risk in obesity. Front Physiol. 2018;9: 253. https://doi.org/10.3389/fphys.2018.00253.

14. Pischon T, Boeing H, Hoffmann K, Bergmann M, Schulze MB, Overvad K, et al. General and abdominal adiposity and risk of death in Europe. N Engl J Med. 2008;359:2105-20. https://doi.org/10.1056/NEJMoa0801891.

15. Pou KM, Massaro JM, Hoffmann U, Vasan RS, Maurovich-Horvat P, Larson $M G$, et al. Visceral and subcutaneous adipose tissue volumes are crosssectionally related to markers of inflammation and oxidative stress: the Framingham heart study. Circulation. 2007;116:1234-41. https://doi.org/10. 1161/CIRCULATIONAHA.107.710509.

16. McLaughlin T, Lamendola C, Liu A, Abbasi F. Preferential fat deposition in subcutaneous versus visceral depots is associated with insulin sensitivity. J Clin Endocrinol Metab. 2011;96:E1756-60. https://doi.org/10.1210/jc.2011-0615.

17. Olzmann JA. Dynamics and functions of lipid droplets. Nat Rev Mol Cell Biol 2019;20(3):137-55. https://doi.org/10.1038/s41580-018-0085-z.

18. Vaughan M, Berger JE, Steinberg D. Hormone-sensitive lipase and Monoglyceride lipase activities in adipose tissue. J Biol Chem. 1964:239:401-9 PMID: 14169138

19. Mitrou P, Raptis SA, Dimitriadis G. Insulin action in morbid obesity: a focus on muscle and adipose tissue. Hormones (Athens). 2013;12:201-13. https:// doi.org/10.14310/horm.2002.1404.

20. Olson AL. Regulation of GLUT4 and insulin-dependent glucose flux. ISRN Mol Biol. 2012;2012:856987. https://doi.org/10.5402/2012/856987.

21. Shen W-J, Patel S, Miyoshi H, Greenberg AS, Kraemer FB. Functional interaction of hormone-sensitive lipase and perilipin in lipolysis. J Lipid Res. 2009;50:2306-13. https://doi.org/10.1194/jlr. M900176-JLR200.

22. Sakaguchi M, Fujisaka S, Cai W, Winnay JN, Konishi M, O’Neill BT, et al. Adipocyte dynamics and reversible metabolic syndrome in mice with an inducible adipocyte-specific deletion of the insulin receptor. Cell Metab. 2017;25:448-62. https://doi.org/10.1016/j.cmet.2016.12.008. 
23. Cook KS, Groves DL, Min HYEY, Spiegelman BM. A developmentally regulated mRNA from $3 T 3$ adipocytes encodes a novel serine protease homologue. Proc Natl Acad Sci U S A. 1985;82:6480-4. https://doi.org/10. 1073/pnas.82.19.6480.

24. Zhang Y, Proenca R, Maffei M, Barone M, Leopold L, Friedman JM. Positional cloning of the mouse obese gene and its human homologue. Nature. 1994; 372. https://doi.org/10.1038/372425a0.

25. Hotamisligil GS, Shargill NS, Spiegelman SB. Adipose expression of tumor necrosis factor-a : direct role in obesity-linked insulin resistance American. Science. 1993;259:87-91.

26. Frederich RC, Lowell BB, Flier JS, Lowell BB, Flier JS. Expression of ob mRNA and its encoded protein in rodents. Impact of nutrition and obesity. J Clin Invest. 1995;96:1658-63. https://doi.org/10.1172/JCl118206.

27. Weigle DS, Raymond C, Kuijper JL. Recombinant Ob protein reduces feeding and body weight in the Ob / Ob mouse. J Clin Invest. 1995;96: 2065-70. https://doi.org/10.1172/JCl118254.

28. Krug AW, Ehrhart-Bornstein M. Newly discovered endocrine functions of white adipose tissue: Possible relevance in obesity-related diseases. Cell and Mol Life Sci. 2005;62:1359-62.

29. Minokoshi Y, Kim YB, Peroni OD, Fryer LGD, Müller C, Carling D, et al. Leptin stimulates fatty-acid oxidation by activating AMP-activated protein kinase. Nature. 2002;415:339-43. https://doi.org/10.1038/415339a.

30. Asilmaz E, Cohen P, Miyazaki M, Dobrzyn P, Ueki K, Fayzikhodjaeva G, et al. Site and mechanism of leptin action in a rodent form of congenital lipodystrophy. J Clin Invest. 2004;113:414-24. https://doi.org/10.1172/ JCl19511.

31. Kubota N, Terauchi Y, Yamauchi T, Kubota T, Moroi M, Matsui J, et al. Disruption of adiponectin causes insulin resistance and neointimal formation. J Biol Chem. 2002;277:25863-6. https://doi.org/10.1074/jbc. C200251200.

32. Komuro R, Matsuzawa $Y$, Nagaretani H, Takahashi M, Furuyama N, Takeda S, et al. Diet-induced insulin resistance in mice lacking adiponectin/ACRP30. Nat Med. 2002;8:731-7. https://doi.org/10.1038/nm724.

33. Shibata R, Ouchi N, Ito M, Kihara S, Shiojima I, Pimentel DR, et al. Adiponectin-mediated modulation of hypertrophic signals in the heart. Nat Med. 2004;10:1384-9. https://doi.org/10.1038/nm1137.

34. Yamauchi T, Kamon J, Ito Y, Tsuchida A, Yokomizo T, Kita S, et al. Cloning of adiponectin receptors that mediate antidiabetic metabolic effects. Nature. 2003:423:762-9. https://doi.org/10.1038/nature01705.

35. Pajvani UB, Du X, Combs TP, Berg AH, Rajala MW, Schulthess T, et al. Structure-function studies of the adipocyte-secreted hormone Acrp30/ adiponectin. Implications fpr metabolic regulation and bioactivity. J Biol Chem. 2003;278:9073-85. https://doi.org/10.1074/jbc. M207198200.

36. Tsao T-S, Murrey HE, Hug C, Lee DH, Lodish HF. Oligomerization statedependent activation of NF-kappa B signaling pathway by adipocyte complement-related protein of $30 \mathrm{kDa}$ (Acrp30). J Biol Chem. 2002;277: 29359-62. https://doi.org/10.1074/jbc. C200312200.

37. Tsao T-S, Tomas E, Murrey HE, Hug C, Lee DH, Ruderman NB, et al. Role of disulfide bonds in Acrp30/adiponectin structure and signaling specificity. Different oligomers activate different signal transduction pathways. J Biol Chem. 2003;278:50810-7. https://doi.org/10.1074/jbc. M309469200.

38. Gupta V, Bhasin S, Guo W, Singh R, Miki R, Chauhan P, et al. Effects of dihydrotestosterone on differentiation and proliferation of human mesenchymal stem cells and preadipocytes. Mol Cell Endocrinol. 2008;296: 32-40. https://doi.org/10.1016/j.mce.2008.08.019.

39. Chazenbalk $G$, Singh $P$, Irge D, Shah A, Abbott DH, Dumesic DA. Androgens inhibit adipogenesis during human adipose stem cell commitment to preadipocyte formation. Steroids. 2013;78:920-6. https://doi.org/10.1016/j. steroids.2013.05.001.

40. Cooke PS, Heine PA, Taylor JA, Lubahn DB. The role of estrogen and estrogen receptor-alpha in male adipose tissue. Mol Cell Endocrinol. 2001; 178:147-54. https://doi.org/10.1016/S0303-7207(01)00414-2.

41. Heine PA, Taylor JA, Iwamoto GA, Lubahn DB, Cooke PS. Increased adipose tissue in male and female estrogen receptor-alpha knockout mice. Proc Natl Acad Sci U S A. 2000;97:12729-34. https://doi.org/10.1073/pnas.97.23.12729.

42. Blouin $K$, Richard C, Bélanger C, Dupont P, Daris M, Laberge $P$, et al. Local androgen inactivation in abdominal visceral adipose tissue. J Clin Endocrinol Metab. 2003;88:5944-50. https://doi.org/10.1210/jc.2003-030535.

43. Blouin K, Blanchette S, Richard C, Dupont P, Luu-The V, Tchernof A. Expression and activity of steroid aldoketoreductases $1 \mathrm{C}$ in omental adipose tissue are positive correlates of adiposity in women. Am J Physiol Endocrinol Metab. 2005;288:E398-404. https://doi.org/10.1152/ajpendo.00312.2004.
44. Blouin K, Richard C, Brochu G, Hould F-S, Lebel S, Marceau S, et al. Androgen inactivation and steroid-converting enzyme expression in abdominal adipose tissue in men. J Endocrinol. 2006;191:637-49. https://doi. org/10.1677/joe.1.06365.

45. Jones ME, Thorburn AW, Britt KL, Hewitt KN, Misso ML, Wreford NG, et al. Aromatase-deficient (ArKO) mice accumulate excess adipose tissue. J Steroid Biochem Mol Biol. 2001;79:3-9. https://doi.org/10.1016/S09600760(01)00136-4.

46. Mathew $\mathrm{H}$, Castracane VD, Mantzoros C. Adipose tissue and reproductive health Metabolism. 2018;86:18-32. https://doi.org/10.1016/j.metabol.2017.11.006.

47. Dobrzyn K, Smolinska N, Kiezun M, Szeszko K, Rytelewska E, Kisielewska K, et al. Adiponectin: a new regulator of female reproductive system. Int J Endocrinol. 2018;2018:7965071. https://doi.org/10.1155/2018/7965071.

48. Jung SM, Sanchez-Gurmaches J, Guertin DA. Brown Adipose Tissue Development and Metabolism. Biochem J. 2018:1-34. https://doi.org/10. 1007/164_2018_168.

49. Cypess AM, Lehman S, Williams G, Tal I, Rodman D, Goldfine AB, et al. Identification and importance of brown adipose tissue in adult humans. $\mathrm{N}$ Engl J Med. 2009;360:1509-17. https://doi.org/10.1056/NEJMoa0810780.

50. Sacks $H$, Symonds ME. Anatomical locations of human brown adipose tissue: functional relevance and implications in obesity and type 2 diabetes. Diabetes. 2013;62:1783-90. https://doi.org/10.2337/db12-1430.

51. Enerback S, Jacobsson A, Simpson E, Guerra C, Yamashita H, Harper M-E, et al. Mice lacking mitochondrial uncoupling protein are cold-sensitve but not obese. Nature. 1997;387:90-4. https://doi.org/10.1038/387090a0.

52. Fedorenko A, Lishko PV, Kirichok Y. Mechanism of fatty-acid-dependent UCP1 uncoupling in brown fat mitochondria. Cell. 2012;151:400-13. https:// doi.org/10.1016/j.cell.2012.09.010.

53. Seale P, Kajimura S, Yang W, Chin S, Rohas LM, Uldry M, et al. Transcriptional control of Brown fat determination by PRDM16. Cell Metab. 2007;6:38-54. https://doi.org/10.1016/j.cmet.2007.06.001

54. Puigserver P, Wu Z, Park CW, Graves R, Wright M, Spiegelman BM. A coldinducible coactivator of nuclear receptors linked to adaptive thermogenesis. Cell. 1998:92:829-39. https://doi.org/10.1016/S0092-8674(00)81410-5.

55. Timmons JA, Wennmalm K, Larsson O, Walden TB, Lassmann T, Petrovic N, et al. Myogenic gene expression signature establishes that brown and white adipocytes originate from distinct cell lineages. Proc Natl Acad Sci. 2007:104:4401-6. https://doi.org/10.1073/pnas.0610615104.

56. Young $P$, Arch JRS, Ashwell M. Brown adipose tissue in the parametrial fat pad of the mouse. FEBS Lett. 1984;167:10-4. https://doi.org/10.1016/00145793(84)80822-4.

57. Guerra C, Koza RA, Yamashita H, Walsh K, Kozak LP. Emergence of brown adipocytes in white fat in mice is under genetic control. Effects on body weight and adiposity. J Clin Invest. 1998;102:412-20. https://doi.org/10.1172/JCl3155.

58. Xue B, Rim J-S, Hogan JC, Coulter AA, Koza RA, Kozak LP. Genetic variability affects the development of brown adipocytes in white fat but not in interscapular brown fat. J Lipid Res. 2006;48:41-51. https://doi.org/10.1194/ jlr. M600287-JLR200

59. López-Soriano FJ, Fernández-López JA, Mampel T, Villarroya F, Iglesias R, Alemany M. Amino acid and glucose uptake by rat brown adipose tissue. Effect of cold-exposure and acclimation. Biochem J. 1988:252:843 LP-849. https://doi.org/10.1042/bj2520843.

60. Scheller EL, Troiano N, Vanhoutan JN, Bouxsein MA, Fretz JA, Xi Y, et al. Use of osmium tetroxide staining with microcomputerized tomography to visualize and quantify bone marrow adipose tissue in vivo. Methods Enzymol. 2014;537:123-39. https://doi.org/10.1016/B978-0-12-411619-1. 00007-0.

61. Lecka-Czernik B, Moerman EJ, Grant DF, Lehmann JM, Manolagas SC, Jilka RL. Divergent effects of selective peroxisome proliferator-activated receptorgamma 2 ligands on adipocyte versus osteoblast differentiation. Endocrinology. 2002;143:2376-84. https://doi.org/10.1210/endo.143.6.8834.

62. Ackert-Bicknell CL, Shockley KR, Horton LG, Lecka-Czernik B, Churchill GA, Rosen CJ. Strain-specific effects of rosiglitazone on bone mass, body composition, and serum insulin-like growth factor-l. Endocrinology. 2009; 150:1330-40. https://doi.org/10.1210/en.2008-0936.

63. Yagi M, Arentsen L, Shanley RM, Rosen CJ, Kidder LS, Sharkey LC, et al. A dual-radioisotope hybrid whole-body micro-positron emission tomography/ computed tomography system reveals functional heterogeneity and early local and systemic changes following targeted radiation to the murine caudal skeleton. Calcif Tissue Int. 2014;94:544-52. https://doi.org/10.1007/ s00223-014-9839-6. 
64. Bolan PJ, Arentsen L, Sueblinvong T, Zhang Y, Moeller S, Carter JS, et al. Water-fat MRI for assessing changes in bone marrow composition due to radiation and chemotherapy in gynecologic cancer patients. J Magn Reson Imaging. 2013;38:1578-84. https://doi.org/10.1002/jmri.24071.

65. Doucette CR, Horowitz MC, Berry R, MacDougald OA, Anunciado-Koza R, Koza RA, et al. A high fat diet increases bone marrow adipose tissue (MAT) but does not Alter trabecular or cortical bone mass in C57BL/6J mice. J Cell Physiol. 2015;230:2032-7. https://doi.org/10.1002/jcp.24954.

66. Bredella MA, Fazeli PK, Daley SM, Miller KK, Rosen CJ, Klibanski A, et al. Marrow fat composition in anorexia nervosa. Bone. 2014;66:199-204. https:// doi.org/10.1016/j.bone.2014.06.014.

67. Ambrosi TH, Scialdone A, Graja A, Gohlke S, Jank A-M, Bocian C, et al. Adipocyte Accumulation in the Bone Marrow during Obesity and Aging Impairs Stem Cell-Based Hematopoietic and Bone Regeneration. Cell Stem Cell. 2017;20:771-784.e6. https://doi.org/10.1016/j.stem.2017.02.009.

68. Chen J, Shi Y, Regan J, Karuppaiah K, Ornitz DM, Long F. Osx-Cre targets multiple cell types besides osteoblast lineage in postnatal mice. PLoS One. 2014;9:e85161. https://doi.org/10.1371/journal.pone.0085161.

69. Ohyama K, Matsumoto Y, Nishimiya K, Hao K, Tsuburaya R, Ota H, et al. Increased coronary perivascular adipose tissue volume in patients with vasospastic angina. Circ J. 2016;80:1653-6. https://doi.org/10.1253/circj. CJ-16-0213.

70. Folkesson M, Vorkapic E, Gulbins E, Japtok L, Kleuser B, Welander M, et al. Inflammatory cells, ceramides, and expression of proteases in perivascular adipose tissue adjacent to human abdominal aortic aneurysms. J Vasc Surg. 2017;65:1171-1179.e1. https://doi.org/10.1016/j.jvs.2015.12.056.

71. Drosos I, Chalikias G, Pavlaki M, Kareli D, Epitropou G, Bougioukas G, et al. Differences between perivascular adipose tissue surrounding the heart and the internal mammary artery: possible role for the leptin-inflammationfibrosis-hypoxia axis. Clin Res Cardiol. 2016;105:887-900. https://doi.org/10. 1007/s00392-016-0996-7.

72. Ozen G, Daci A, Norel X, Topal G. Human perivascular adipose tissue dysfunction as a cause of vascular disease: focus on vascular tone and wall remodeling. Eur J Pharmacol. 2015;766:16-24. https://doi.org/10.1016/j. ejphar.2015.09.012

73. Maenhaut N, Van de Voorde J. Regulation of vascular tone by adipocytes. BMC Med. 2011;9:25. https://doi.org/10.1186/1741-7015-9-25.

74. Miao C-Y, Li Z-Y. The role of perivascular adipose tissue in vascular smooth muscle cell growth. Br J Pharmacol. 2012;165:643-58. https://doi.org/10. 1111/j.1476-5381.2011.01404.x.

75. Takaoka M, Suzuki H, Shioda S, Sekikawa K, Saito Y, Nagai R, et al. Endovascular injury induces rapid phenotypic changes in perivascular adipose tissue. Arterioscler Thromb Vasc Biol. 2010;30:1576-82. https://doi. org/10.1161/ATVBAHA.110.207175.

76. Salgado-Somoza A, Teijeira-Fernández E, Fernández ÁL, González-Juanatey JR, Eiras S, Salgado-Somoza A, et al. Proteomic analysis of epicardial and subcutaneous adipose tissue reveals differences in proteins involved in oxidative stress. Am J Physiol Circ Physiol. 2010;299:H202-9. https://doi.org/ 10.1152/ajpheart.00120.2010.

77. Imaizumi K. Diet and atherosclerosis in apolipoprotein E-deficient mice. Biosci Biotechnol Biochem. 2011;75:1023-35. https://doi.org/10.1271/bbb. 110059.

78. Öhman MK, Luo W, Wang H, Guo C, Abdallah W, Russo HM, et al. Perivascular visceral adipose tissue induces atherosclerosis in apolipoprotein E deficient mice. Atherosclerosis. 2011;219:33-9. https://doi.org/10.1016/j. atherosclerosis.2011.07.012

79. Chang L, Villacorta L, Li R, Hamblin M, Xu W, Dou C, et al. Loss of perivascular adipose tissue on peroxisome proliferator-activated receptor- $\gamma$ deletion in smooth muscle cells impairs intravascular thermoregulation and enhances atherosclerosis. Circulation. 2012;126:1067-78. https://doi.org/10. 1161/CIRCULATIONAHA.112.104489.

80. Guzik B, Sagan A, Ludew D, Mrowiecki W, Chwala M, Bujak-Gizycka B, et al. Mechanisms of oxidative stress in human aortic aneurysms--association with clinical risk factors for atherosclerosis and disease severity. Int J Cardiol. 2013;168:2389-96. https://doi.org/10.1016/j.ijcard.2013.01.278.

81. Boucher JM, Robich M, Scott SS, Yang X, Ryzhova L, Turner JE, et al. Rab27a Regulates Human Perivascular Adipose Progenitor Cell Differentiation. Cardiovasc Drugs Ther. 2018:519-30. https://doi.org/10.1007/s10557-018-6813-y.

82. Kershaw EE, Flier JS. Adipose Tissue as an Endocrine Organ. J Clin Endocrinol Metab. 2004;89:2548-56. https://doi.org/10.1210/jc.2004-0395.

83. Bråkenhielm E, Cao R, Gao B, Angelin B, Cannon B, Parini $P$, et al. Angiogenesis inhibitor, TNP-470, prevents diet induced and genetic obesity in mice. Circ Res. 2004;94:1579-88. https://doi.org/10.1161/01.RES 0000132745.76882 .70$.

84. Cao Y. Angiogenesis modulates adipogenesis and obesity. J Clin Invest. 2007;71:1-22. https://doi.org/10.1172/JCl32239.2362.

85. Klöting N, Blüher M. Adipocyte dysfunction, inflammation and metabolic syndrome. Rev Endocr Metab Disord. 2014;15:277-87. https://doi.org/10. 1007/s11154-014-9301-0

86. Marette A. Mediators of cytokine-induced insulin resistance in obesity and other inflammatory settings. Curr Opin Clin Nutr Metab Care. 2002;5:377-83 PMID: 12107372

87. Oh DY, Morinaga H, Talukdar S, Bae EJ, Olefsky JM. Increased macrophage migration into adipose tissue in obese mice. Diabetes. 2012;61:346-54. https://doi.org/10.2337/db11-0860.

88. Berg $\mathrm{AH}$, Scherer PE. Adipose tissue, inflammation, and cardiovascular disease. Circ Res. 2005;96:939-49. https://doi.org/10.1161/01.RES.0000163635. 62927.34.

89. Lau DCW, Dhillon K, Yan H, Szmitko P, Verma S. Adipokines: molecular links between obesity and atheroslcerosis. Am J Physiol Heart Circ Physiol. 2005; 288:2031-41. https://doi.org/10.1152/ajpheart.01058.2004.

90. Hutmacher DW. Scaffold design and fabrication technologies for engineering tissues - state of the art and future perspectives. J Biomater Sci Polym Ed. 2001;12:107-24 PMID: 11334185.

91. Fitzgerald KA. Malhotra M, Curtin CM, O' Brien FJ, O' Driscoll CM. Life in 3D is never flat: 3D models to optimise drug delivery. J Control Release. 2015; 215:39-54. https://doi.org/10.1016/j.jconrel.2015.07.020.

92. Baker EL, Bonnecaze RT, Zaman MH. Extracellular matrix stiffness and architecture govern intracellular rheology in cancer. Biophys J. 2009;97: 1013-21. https://doi.org/10.1016/j.bpj.2009.05.054.

93. Ng M, Fleming T, Robinson M, Thomson B, Graetz N, Margono C, et al. Global, regional, and national prevalence of overweight and obesity in children and adults during 1980-2013: a systematic analysis for the global burden of disease study 2013. Lancet. 2014;384:766-81. https://doi.org/10. 1016/S0140-6736(14)60460-8.

94. Cawley J, Meyerhoefer C. The medical care costs of obesity: an instrumental variables approach. J Health Econ. 2012;31:219-30. https://doi.org/10.1016/j. jhealeco.2011.10.003.

95. Abdullah A, Peeters A, de Courten M, Stoelwinder J. The magnitude of association between overweight and obesity and the risk of diabetes: a meta-analysis of prospective cohort studies. Diabetes Res Clin Pract. 2010;89: 309-19. https://doi.org/10.1016/j.diabres.2010.04.012

96. Willett WC, Rimm EB, Flint AJ, Manson JE, Hu FB, Glynn RJ, et al. Excess weight and the risk of incident coronary heart disease among men and women. Obesity. 2009;18:377-83. https://doi.org/10.1038/oby.2009.223.

97. Polednak AP. Estimating the number of U.S. incident cancers attributable to obesity and the impact on temporal trends in incidence rates for obesityrelated cancers. Cancer Detect Prev. 2008;32:190-9. https://doi.org/10.1016/j. cdp.2008.08.004

98. Koza RA, Nikonova L, Hogan J, Rim J-S, Mendoza T, Faulk C, et al. Changes in gene expression foreshadow diet-induced obesity in genetically identical mice. PLoS Genet. 2006;2:e81. https://doi.org/10.1371/journal.pgen.0020081.

99. Fehlert E, Wagner R, Ketterer C, Bohm A, Machann J, Fritsche L, et al. Genetic determination of body fat distribution and the attributive influence on metabolism. Obesity (Silver Spring). 2017;25:1277-83. https:/doi.org/10.1002/oby.21874.

100. Lehnig AC, Stanford KI. Exercise-induced adaptations to white and brown adipose tissue. J Exp Biol. 2018;221(Pt Suppl 1). https://doi.org/10.1242/jeb.161570.

101. Haczeyni F, Barn V, Mridha AR, Yeh MM, Estevez E, Febbraio MA, et al. Exercise improves adipose function and inflammation and ameliorates fatty liver disease in obese diabetic mice. Obesity (Silver Spring). 2015;23:184555. https://doi.org/10.1002/oby.21170.

102. Strawford A, Antelo F, Christiansen M, Hellerstein MK. Adipose tissue triglyceride turnover, de novo lipogenesis, and cell proliferation in humans measured with 2H2O. Am J Physiol Endocrinol Metab. 2004;286:E577-88. https://doi.org/10.1152/ajpendo.00093.2003.

103. Trayhurn P, Wang B, Wood IS. Hypoxia in adipose tissue: a basis for the dysregulation of tissue function in obesity? Br J Nutr. 2008;100:227-35. https://doi.org/10.1017/S0007114508971282.

104. Kabon B, Nagele A, Reddy D, Eagon C, Fleshman JW, Sessler DI, et al. Obesity decreases perioperative tissue oxygenation. Anesthesiology. 2004; 100:274-80 PMID: 14739800.

105. Virtanen KA, Lönnroth $P$, Parkkola R, Peltoniemi $P$, Asola M, Viljanen $T$, et al. Glucose uptake and perfusion in subcutaneous and visceral adipose tissue 
during insulin stimulation in nonobese and obese humans. J Clin Endocrinol Metab. 2014;87:3902-10. https://doi.org/10.1210/jcem.87.8.8761.

106. Ozcan U. Chemical Chaperones Reduce ER Stress and Restore Glucose Homeostasis in a Mouse Model of Type 2 Diabetes. Science. 2006;313:113740. https://doi.org/10.1126/science.1128294.

107. Wang QA, Tao C, Gupta RK, Scherer PE. Tracking adipogenesis during white adipose tissue development, expansion and regeneration. Nat Med. 2013;19: 1338-44. https://doi.org/10.1038/nm.3324.

108. Cinti S, Mitchell G, Barbatelli G, Murano I, Ceresi E, Faloia E, et al. Adipocyte death defines macrophage localization and function in adipose tissue of obese mice and humans. J Lipid Res. 2005;46:2347-55. https://doi.org/10. 1194/jlr. M500294-JLR200.

109. Kanda H, Tateya S, Tamori Y, Kotani K, Hiasa K, Kitazawa R, et al. MCP-1 contributes to macrophage infiltration into adipose tissue, insulin resistance, and hepatic steatosis in obesity. J Clin Invest. 2006;116:1494-505. https://doi org/10.1172/JCI26498.

110. Engin A, Engin A. Obesity and Lipotoxicity. Advances in Exp. Medicine and Biology. 1st ed. Cham: Springer Nature; 2017. https://doi.org/10.1007/978-3319-48382-5.

111. Zeyda M, Stulnig TM. Obesity, inflammation, and insulin resistance - a mini-review. Gerontology. 2009;55:379-86. https://doi.org/10.1159/ 000212758 .

112. Miller RS, Diaczok D, Cooke DW. Repression of GLUT4 expression by the endoplasmic reticulum stress response in 3T3-L1 adipocytes. Biochem Biophys Res Commun. 2007;362:188-92. https://doi.org/10.1016/j.bbrc.2007.07.176.

113. Huber J, Kiefer FW, Zeyda M, Ludvik B, Silberhumer GR, Prager G, et al. CC chemokine and CC chemokine receptor profiles in visceral and subcutaneous adipose tissue are altered in human obesity. J Clin Endocrinol Metab. 2008;93:3215-21. https://doi.org/10.1210/jc.2007-2630.

114. Zeyda M, Farmer D, Aszmann O, Speiser M, Györi G, Todoric J, et al. Human adipose tissue macrophages are of an anti-inflammatory phenotype but capable of excessive pro-inflammatory mediator production. Int J Obes. 2007:31:1420-8. https://doi.org/10.1038/sj.ijo.0803632.

115. Hopkins AM, DeSimone E, Chwalek K, Kaplan DL. 3D in vitro modeling of the central nervous system. Prog Neurobiol. 2015;125:1-25. https://doi.org/ 10.1016/j.pneurobio.2014.11.003.

116. Murphy AR, Laslett A, O'Brien CM, Cameron NR. Scaffolds for $3 D$ in vitro culture of neural lineage cells. Acta Biomater. 2017:54:1-20. https://doi.org/ 10.1016/j.actbio.2017.02.046.

117. Knowlton S, Anand S, Shah T, Tasoglu S. Bioprinting for neural tissue engineering. Trends Neurosci. 2018;41:31-46. https://doi.org/10.1016/j.tins.2017.11.001.

118. Mobini S, Song YH, McCrary MW, Schmidt CE. Advances in ex vivo models and lab-on-a-chip devices for neural tissue engineering. Biomaterials. 2019; 198:146-66. https://doi.org/10.1016/j.biomaterials.2018.05.012.

119. Emont MP, Yu H, Jun H, Hong X, Maganti N, Stegemann JP, et al. Using a $3 \mathrm{D}$ culture system to differentiate visceral adipocytes in vitro. Endocrinology. 2015;156:4761-8. https://doi.org/10.1210/en.2015-1567.

120. Davidenko N, Campbell JJ, Thian ES, Watson CJ, Cameron RE. Collagenhyaluronic acid scaffolds for adipose tissue engineering. Acta Biomater. 2010;6:3957-68. https://doi.org/10.1016/j.actbio.2010.05.005

121. Turner PA, Tang Y, Weiss SJ, Janorkar AV. Three-dimensional spheroid cell model of in vitro adipocyte inflammation. Tissue Eng Part A. 2015;21:183747. https://doi.org/10.1089/ten. TEA.2014.0531.

122. Vidyasekar $P$, Shyamsunder $P$, Sahoo SK, Verma RS. Scaffold-free and scaffold-assisted 3D culture enhances differentiation of bone marrow stromal cells. Vitr Cell Dev Biol - Anim. 2016;52:204-17. https://doi.org/10. 1007/s11626-015-9971-2.

123. Kuss M, Kim J, Qi D, Wu S, Lei Y, Chung S, et al. Effects of tunable, 3D-bioprinted hydrogels on human brown adipocyte behavior and metabolic function. Acta Biomater. 2018;71:486-95. https://doi.org/10.1016/j.actbio.2018.03.021.

124. Hsiao AY, Okitsu T, Teramae H, Takeuchi S. 3D Tissue Formation of Unilocular Adipocytes in Hydrogel Microfi bers. Adv Healthc Mater. 2016: 548-56. https://doi.org/10.1002/adhm.201500673.

125. Mauney JR, Nguyen T, Gillen K, Kirker-Head C, Gimble JM, Kaplan DL. Engineering adipose-like tissue in vitro and in vivo utilizing human bone marrow and adipose-derived mesenchymal stem cells with silk fibroin 3D scaffolds. Biomaterials. 2007;28:5280-90. https://doi.org/10.1016/j. biomaterials.2007.08.017.

126. Bellas E, Marra KG, Kaplan DL. Sustainable three-dimensional tissue model of human adipose tissue. Tissue Eng Part C Methods. 2013;19:745-54. https:// doi.org/10.1089/ten.tec.2012.0620
127. Abbott RD, Raja WK, Wang RY, Stinson JA, Glettig DL, Burke KA, et al. Long term perfusion system supporting adipogenesis. Methods. 2015;84:84-9. https://doi.org/10.1016/j.ymeth.2015.03.022.

128. Aubin K, Safoine M, Proulx M, Audet-Casgrain M-A, Cote J-F, Tetu F-A, et al. Characterization of in vitro engineered human adipose tissues: relevant Adipokine secretion and impact of TNF-alpha. PLoS One. 2015;10:e0137612. https://doi.org/10.1371/journal.pone.0137612.

129. Aubin K, Vincent C, Proulx M, Mayrand D, Fradette J. Creating capillary networks within human engineered tissues: impact of adipocytes and their secretory products. Acta Biomater. 2015;11:333-45. https://doi.org/10.1016/j. actbio.2014.09.044

130. Qi D, Wu S, Kuss MA, Shi W, Chung S, Deegan PT, et al. Mechanically robust cryogels with injectability and bioprinting supportability for adipose tissue engineering. Acta Biomater. 2018;74:131-42. https://doi.org/10.1016/j.actbio. 2018.05.044.

131. Daquinag AC, Souza GR, Kolonin MG. Adipose tissue engineering in threedimensional levitation tissue culture system based on magnetic nanoparticles. Tissue Eng Part C Methods. 2013;19:336-44. https://doi.org/ 10.1089/ten. TEC.2012.0198

132. Choi JH, Gimble JM, Vunjak-Novakovic G, Kaplan DL. Effects of hyperinsulinemia on Lipolytic function of three-dimensional adipocyte/ endothelial co-cultures. Tissue Eng Part C Methods. 2010;16:1157-65. https://doi.org/10.1089/ten. TEC.2009.0760.

133. Abbott RD, Wang RY, Reagan MR, Chen Y, Borowsky FE, Zieba A, et al. The Use of Silk as a Scaffold for Mature, Sustainable Unilocular Adipose 3D Tissue Engineered Systems. Adv Healthc Mater. 2016:1667-77. https://doi. org/10.1002/adhm.201600211.

134. Das S, Pati F, Choi YJ, Rijal G, Shim JH, Kim SW, et al. Bioprintable, cell-laden silk fibroin-gelatin hydrogel supporting multilineage differentiation of stem cells for fabrication of three-dimensional tissue constructs. Acta Biomater. 2015;11:233-46. https://doi.org/10.1016/j.actbio.2014.09.023.

135. Proulx M, Safoine M, Mayrand D, Aubin K, Maux A, Fradette J. Impact of TNF and IL-1 $\beta$ on capillary networks within engineered human adipose tissues. J Mater Chem B. 2016:4:3608-19. https://doi.org/10.1039/C6TB00265J.

136. Proulx M, Mayrand D, Vincent C, Boisvert A, Aubin K, Trottier V, et al. Shortterm post-implantation dynamics of in vitro engineered human microvascularized adipose tissues. Biomed Mater. 2018;13:65013. https://doi. org/10.1088/1748-605X/aadff7.

137. Yang Y, Yang X, Zou J, Jia C, Hu Y, Du H, et al. Evaluation of photodynamic therapy efficiency using an in vitro three-dimensional microfluidic breast cancer tissue model. Lab Chip. 2015;15:735-44. https://doi.org/10.1039/ c4lc01065e.

138. Dunne LW, Huang Z, Meng W, Fan X, Zhang N, Zhang Q, et al. Human decellularized adipose tissue scaffold as a model for breast cancer cell growth and drug treatments. Biomaterials. 2014;35:4940-9. https://doi.org/ 10.1016/j.biomaterials.2014.03.003

139. Campbell JJ, Botos L-A, Sargeant TJ, Davidenko N, Cameron RE, Watson CJ. A 3-D in vitro co-culture model of mammary gland involution. Integr Biol (Camb). 2014:6:618-26. https://doi.org/10.1039/c3ib40257f.

140. Hume RD, Berry L, Reichelt S, D'Angelo M, Gomm J, Cameron RE, et al. An engineered human adipose/collagen model for in vitro breast Cancer cell migration studies. Tissue Eng Part A. 2018;24:1309-19. https://doi.org/10. 1089/ten. TEA.2017.0509.

141. Hume RD, Pensa S, Brown EJ, Kreuzaler PA, Hitchcock J, Husmann A, et al. Tumour cell invasiveness and response to chemotherapeutics in adipocyte invested 3D engineered anisotropic collagen scaffolds. Sci Rep. 2018:8:1-15. https://doi.org/10.1038/s41598-018-30107-3.

142. Bougaret L, Delort L, Billard H, Le Huede C, Boby C, De la Foye A, et al. Adipocyte/breast cancer cell crosstalk in obesity interferes with the antiproliferative efficacy of tamoxifen. PLoS One. 2018;13:e0191571. https://doi. org/10.1371/journal.pone.0191571.

143. Mosaad E, Chambers K, Futrega K, Clements J, Doran MR. Using high throughput microtissue culture to study the difference in prostate cancer cell behavior and drug response in 2D and 3D co-cultures. BMC Cancer. 2018;18:1-11. https://doi.org/10.1186/s12885-018-4473-8.

144. Herroon MK, Diedrich JD, Podgorski I. New 3D-culture approaches to study interactions of bone marrow adipocytes with metastatic prostate cancer cells. Front Endocrinol (Lausanne). 2016;7:84. https://doi.org/10.3389/fendo. 2016.00084

145. Ito M, Grujic D, Abel ED, Vidal-Puig A, Susulic VS, Lawitts J, et al. Mice expressing human but not murine beta3-adrenergic receptors under the 
control of human gene regulatory elements. Diabetes. 1998;47:1464-71. https://doi.org/10.2337/diabetes.47.9.1464.

146. Mackay F, Rothe J, Bluethmann H, Loetscher H, Lesslauer W. Differential responses of fibroblasts from wild-type and TNF-R55-deficient mice to mouse and human TNF-alpha activation. J Immunol. 1994;153:5274-84 PMID: 7525730.

147. Kuprash DV, Udalova IA, Turetskaya RL, Kwiatkowski D, Rice NR, Nedospasov SA. Similarities and differences between human and murine TNF promoters in their response to lipopolysaccharide. J Immunol. 1999;162:4045-52 PMID; 10201927.

148. Hixon KR, Lu T, Sell SA. A comprehensive review of cryogels and their roles in tissue engineering applications. Acta Biomater. 2017;62:29-41. https://doi. org/10.1016/j.actbio.2017.08.033.

149. Souza GR, Christianson DR, Staquicini Fl, Ozawa MG, Snyder EY, Sidman RL, et al. Networks of gold nanoparticles and bacteriophage as biological sensors and cell-targeting agents. Proc Natl Acad Sci. 2006;103:1215-20. https://doi.org/10.1073/pnas.0509739103.

150. Abbott RD, Borowsky FE, Alonzo CA, Zieba A, Georgakoudi I, Kaplan DL. Variability in responses observed in human white adipose tissue models. J Tissue Eng Regen Med. 2018;12:840-7. https://doi.org/10.1002/term.2572.

151. Dadwal U, Falank C, Fairfield H, Linehan S, Rosen CJ, Kaplan DL, et al. Tissueengineered 3D cancer-in-bone modeling: silk and PUR protocols. Bonekey Rep. 2016;5:842. https://doi.org/10.1038/bonekey.2016.75.

152. Huang Y, Dai Z-Q, Ling S-K, Zhang H-Y, Wan Y-M, Li Y-H. Gravity, a regulation factor in the differentiation of rat bone marrow mesenchymal stem cells. J Biomed Sci. 2009:16:87. https://doi.org/10.1186/1423-0127-16-87.

153. Wang X, Reagan MR, Kaplan DL. Synthetic adipose tissue models for studying mammary gland development and breast tissue engineering. J Mammary Gland Biol Neoplasia. 2010;15:365-76. https://doi.org/10.1007/ s10911-010-9192-y.

154. Ding Y, Liu W, Yu W, Lu S, Liu M, Kaplan DL, et al. Three-dimensional tissue culture model of human breast cancer for the evaluation of multidrug resistance. J Tissue Eng Regen Med. 2018;12:1959-71. https://doi.org/10. 1002/term.2729.

155. Delort L, Lequeux C, Dubois V, Dubouloz A, Billard H, Mojallal A, et al. Reciprocal interactions between breast tumor and its adipose microenvironment based on a 3D adipose equivalent model. PLoS One. 2013;8:e66284. https://doi.org/10.1371/journal.pone.0066284.

156. Reagan MR, Mishima Y, Glavey S V, Zhang Y, Manier S, Lu ZN, et al. Investigating osteogenic differentiation in multiple myeloma using a novel 3D bone marrow niche model. Blood. 2014;124:3250-9.

157. Su S, Guntur AR, Nguyen DC, Fakory SS, Doucette CC, Leech C, et al. A Renewable Source of Human Beige Adipocytes for Development of Therapies to Treat Metabolic Syndrome. Cell Rep. 2018;25:3215-3228.e9. https://doi.org/10.1016/j.celrep.2018.11.037.

158. Hussain I, Garg A. Lipodystrophy syndromes. Endocrinol Metab Clin N Am. 2016:45:783-97. https://doi.org/10.1016/j.ecl.2016.06.012.

\section{Publisher's Note}

Springer Nature remains neutral with regard to jurisdictional claims in published maps and institutional affiliations.

Ready to submit your research? Choose BMC and benefit from:

- fast, convenient online submission

- thorough peer review by experienced researchers in your field

- rapid publication on acceptance

- support for research data, including large and complex data types

- gold Open Access which fosters wider collaboration and increased citations

- maximum visibility for your research: over $100 \mathrm{M}$ website views per year

At BMC, research is always in progress.

Learn more biomedcentral.com/submissions 